\title{
A WEE1 family business: regulation of mitosis, cancer progression, and therapeutic target
}

\author{
Andrea Ghelli Luserna di Rorà, Claudio Cerchione, Giovanni Martinelli and Giorgia Simonetti *i
}

\begin{abstract}
The inhibition of the DNA damage response (DDR) pathway in the treatment of cancer has recently gained interest, and different DDR inhibitors have been developed. Among them, the most promising ones target the WEE1 kinase family, which has a crucial role in cell cycle regulation and DNA damage identification and repair in both nonmalignant and cancer cells. This review recapitulates and discusses the most recent findings on the biological function of WEE1/PKMYT1 during the cell cycle and in the DNA damage repair, with a focus on their dual role as tumor suppressors in nonmalignant cells and pseudo-oncogenes in cancer cells. We here report the available data on the molecular and functional alterations of WEE1/PKMYT1 kinases in both hematological and solid tumors. Moreover, we summarize the preclinical information on 36 chemo/radiotherapy agents, and in particular their effect on cell cycle checkpoints and on the cellular WEE1/PKMYT1-dependent response. Finally, this review outlines the most important pre-clinical and clinical data available on the efficacy of WEE1/PKMYT1 inhibitors in monotherapy and in combination with chemo/radiotherapy agents or with other selective inhibitors currently used or under evaluation for the treatment of cancer patients.
\end{abstract}

Keywords: WEE1 family kinases, WEE1, PKMYT1, Cell cycle, DNA repair, Pseudo-oncogene, Tumor suppressor

\section{Background}

The WEE1 kinase family consists of three serine/threonine kinases sharing conserved molecular structures and encoded by the following genes: WEE1 (WEE1 G2 Checkpoint Kinase), PKMYT1 (membrane-associated tyrosine- and threonine-specific cdc2-inhibitory kinase), and WEE1B (WEE2 oocyte meiosis inhibiting kinase). In eukaryotic somatic cells, WEE1 and PKMYT1 play a key role in cell cycle regulation and, in particular, they are involved in the entry into mitosis [1]. Their role as regulators is crucial during normal cell cycle progression and in response to DNA damages, as part of the DNA damage response (DDR) pathways. Similarly, WEE2 regulates cell

\footnotetext{
* Correspondence: giorgia.simonetti@irst.emr.it

Biosciences Laboratory (Onco-hematology Unit), Istituto Scientifico Romagnolo per lo Studio e la Cura dei Tumori (IRST) IRCCS, Via P. Maroncelli 40, 47014 Meldola, FC, Italy
}

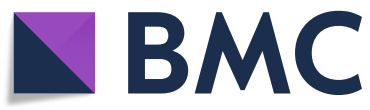

(c) The Author(s). 2020 Open Access This article is licensed under a Creative Commons Attribution 4.0 International License, which permits use, sharing, adaptation, distribution and reproduction in any medium or format, as long as you give appropriate credit to the original author(s) and the source, provide a link to the Creative Commons licence, and indicate if changes were made. The images or other third party material in this article are included in the article's Creative Commons licence, unless indicated otherwise in a credit line to the material. If material is not included in the article's Creative Commons licence and your intended use is not permitted by statutory regulation or exceeds the permitted use, you will need to obtain permission directly from the copyright holder. To view a copy of this licence, visit http://creativecommons.org/licenses/by/4.0/ The Creative Commons Public Domain Dedication waiver (http://creativecommons.org/publicdomain/zero/1.0/) applies to the data made available in this article, unless otherwise stated in a credit line to the data.
WEE1 and PKMYT1 act as tumor suppressors in nonmalignant eukaryotic somatic cells. Similarly to other DDR-related kinases, their main biological function is to cycle progression and, in particular, meiosis [2]. Briefly, WEE2 plays a dual regulatory role in oocyte meiosis by preventing premature restart prior to ovulation and permitting metaphase II exit at fertilization [3]. Despite the identification of WEE2 somatic mutations (1.9\% of cases) and copy number $(\mathrm{CN})$ alterations $(22.5 \%$ of patients with $\mathrm{N}$ loss and $22.5 \%$ with $\mathrm{CN}$ gain) across several cancer ypes (https://portal.gdc.cancer.gov), they have not been functionally linked to tumor development so far. Therefere the following sections will be focused on WEE1 and PKMYT1 kinases that have a well-recognized role in oncology and hemato-oncology.

\section{WEE1 and PKMYT1 in cell cycle regulation}


prevent replication of cells with altered DNA. The main downstream target of WEE1 family kinases is the cyclin-dependent kinase 1 (CDK1)-cyclin B1 complex, also known as mitotic-promoting factor (MPF). WEE1 phosphorylates CDK1 on Tyr15 while PKMYT1 has a dual activity on Tyr15 and Thr14 [4] (Fig. 1a). The phosphorylation of those residues keeps the MPF complex inhibited until the cell approaches mitosis. WEE1 is located in the nucleus, while PKMYT1 is associated with the endoplasmic reticulum and Golgi apparatus [5, 6], and regulates Golgi membrane reassembly following mitosis [7]. Together, WEE1 and PKMYT1 ensure that CDK1 remains inactive as it shuttles into and out of the nucleus [8]. Through its extra-nuclear localization, PKMYT1 can also promote CDK1 cytosolic segregation. At the G2/M border, if no DNA damage has been detected, CDK1 phosphorylation on Tyr 15 and Thr 14 is rapidly removed by CDC $25 \mathrm{C}$ phosphatase. In the nucleus, the CDK-activating kinase (CAK) complex composed by cyclin-dependent kinase 7 (CDK7), cyclin H1, and MAT1 promotes MPF complex activation through the phosphorylation of CDK1(Thr161) $[9,10]$. The active MPF complex is then imported into the nucleus through phosphorylation of cyclin B1 (Ser126, Ser128, Ser133, and Ser147) [11]. This event is required to enter mitosis. The relevance of WEE1 and PKMYT1 regulation of CDK1 has been recently confirmed by in vivo studies. Indeed, the replacement of the CDK1 inhibitory phosphorylation sites with non-phosphorylatable amino acids $\left(\mathrm{CDK} 1^{\mathrm{T} 14 \mathrm{~A} / \mathrm{Y} 15 \mathrm{~F}}\right)$ was embryonic lethal in mice [12]. Once activated, the MPF complex can phosphorylate
WEE1 and PKMYT1 to promote their inactivation via different cascades [5, 13, 14]. WEE1 is phosphorylated (Ser123) by CDK1 at the onset of mitosis, thereby generating a binding motif for polo like kinase 1 (PLK1) and casein kinase 2 (CK2), that in turn phosphorylate WEE1 (Ser53 and Ser121, respectively) [14, 15]. Together, the phosphorylation of the three Ser residues serves as a tag for the degradation of WEE1 by the ubiquitin ligase SCF $\beta$ TrCP [13]. PKMYT1 is also phosphorylated by CDK1 and PLK1 and this event promotes its degradation [16]. In addition to the checkpoint function at the G2/M border, recent findings highlighted a role of WEE1 in the regulation of replication dynamics during $\mathrm{S}$ phase (intra $\mathrm{S}$ phase checkpoint). When cells reach the $S$ phase, replication is initiated from a large number of replication origins triggered through the activation of the pre-replication complex [17] and following the activation of $S$ phase specific CDK, primarily CDK2 $[18,19]$. Similarly to CDK1, CDK2 regulation is controlled through Tyr15 phosphorylation status, that is balanced by WEE1 (Fig. 1a) and cell division cycle 25A (CDC25A) activity [20]. Both WEE1 and CDC25A/C have been shown to modulate unperturbed replication through regulating CDK1/CDK2 activity. Monoallelic expression of CDK1 $1^{\mathrm{T} 14 \mathrm{~A} / \mathrm{Y} 15 \mathrm{~F}}$ induced replication stress and $\mathrm{S}$ phase arrest in mouse embryonic fibroblasts (MEFs), with substantial increase of $\gamma \mathrm{H} 2 \mathrm{AX}$ levels, chromosomal fragmentation, and DDR activation, as a consequence of intra-S phase DNA damage [12]. Moreover, unscheduled origin firing due to loss of WEE1 leads to exhaustion of the replication protein A1 (RPA1) pool and, as a consequence, to death during DNA replication
A

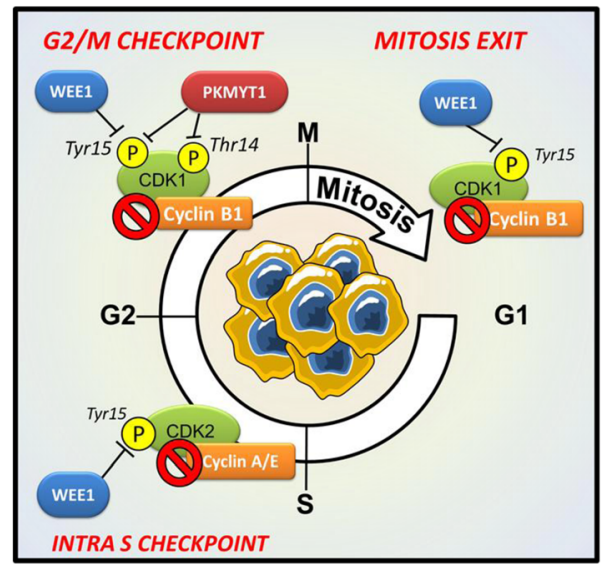

\section{B}

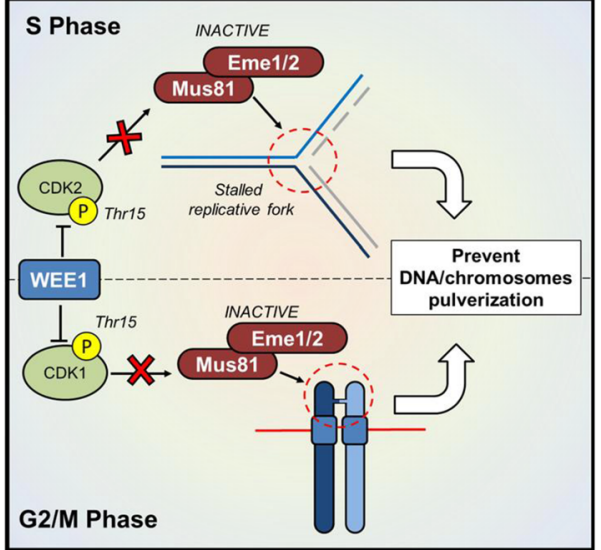

Fig. 1 WEE1 and PKMYT1 biological functions. a Schematic representation of WEE1 and PKMYT1 involvement in cell cycle checkpoints. WEE1 regulates the activity of both CDK1 and CDK2 kinases (trough phosphorylation of Tyr15) and is involved in the regulation of intra-S, G2/M, and M phase cell cycle checkpoints. PKMYT1 selectively regulates CDK1 (through phosphorylation of Tyr15 and Thr14) and is plays a role in the G2/M phase checkpoint. $\mathbf{b}$ Schematic representation of the regulation of MUS81-EME1/2 endonuclease complexes by WEE1 during S and G2/M cell cycle phases. By inhibiting CDK2 or CDK1, WEE1 prevents MUS81 activation and the generation of DNA damages during $S$ phase, and chromosomes pulverization during G2/M phase 
(replication catastrophe). The intra S phase activity of WEE1 is independent from PKMYT1 that is unable to phosphorylate CDK2 [5]. In addition, WEE1, but not PKMYT1, contributes to the control of mitosis exit. Indeed, Wee1-deficient MEFs showed mitotic defects (e.g., in the number and position of centrosomes) that induce arrest in mitosis or, in the majority of cells, mitotic slippage [21, 22]. At the end of mitosis, WEE1 inhibits CDK1 through phosphorylation of its Tyr15 residue (Fig. 1a). This event is dependent on the activation of the CTD phosphatase subunit 1 (FCP1) that dephosphorylates and activates WEE1 and other crucial component of the spindle assembly checkpoint (SAC) complex [23]. Although the precise mechanisms that regulate FCP1 activity is still unknown, it has been showed that FCP1 promotes the dephosphorylation of crucial SAC components, including cell division cycle 20 (CDC20) and ubiquitin specific peptidase 44 (USP44), thus promoting $\mathrm{APC} / \mathrm{C}^{\mathrm{Cdc} 20}$ activation and chromosome segregation [24-26]. Moreover, WEE1 directly interacts with APC/C components, including fizzy and cell division cycle 20 related 1 (CDH1), CDC20, cell division cycle 27 (CDC27), and its deletion enforced $\mathrm{APC} / \mathrm{C}$ activity, resulting in alterations of the level of $\mathrm{APC} / \mathrm{C}$ substrates and mitosis progression at the expense of genomic stability [21].

\section{WEE1 regulates replication forks and genome stability}

The activity of WEE1 through the cell cycle can explain its tumor suppressor function, at least in nonmalignant cells. This observation was confirmed and disentangled in preclinical studies. Indeed, conditional Wee1 heterozygous deletion in the murine mammary epithelium caused enhanced proliferation, with cells progressing into mitosis while still undergoing DNA replication, and consequent accumulation of DNA damage, resulting in genomic instability and, ultimately, in tumor development [21]. Biological processes such as DNA replication and homologous recombination involve the formation of branched DNA structures that physically link chromosomes. Such DNA structures needs to be disengaged prior to entry into mitosis, in order to ensure proper chromosome segregation. Eukaryotic cells evolved different mechanisms to identify and process branched DNA structures (Y-shape DNA) and the most important one involves the structure-selective endonuclease MUS81. MUS81 forms heterodimeric complexes with the noncatalytic subunits EME1 or EME2 and recognizes Yshape DNA structures during DNA replication or during mitosis (homologous recombination). The activity of MUS81-EME1/2 complex is crucial to recover stalled replication forks, during prolonged $\mathrm{S}$ phase arrest, and to reset DNA junction between twin chromatids during homologous recombination [27]. In unperturbed cells,
WEE1 protects replication forks and prevents the generation DNA damages and chromosome pulverization through an indirect inhibition of MUS81 functionality [28]. Indeed, WEE1 phosphorylates CDK1 and CDK2, thus preventing the CDK-mediated phosphorylation and activation of MUS81-EME1/2 complexes [29]. Lack of WEE1-dependent regulation of MUS81-EME1/2 endonucleases may lead to cleavage of unwanted DNA structure (excessive replication forks), which would slow down replication progression and increase genomic instability [27, 28] (Fig. 1b).

\section{WEE1 and PKMYT1 deregulation in cancer cells WEE1 and PKMYT1 act like oncogenes}

The biological role of WEE1 and PKMYT1 in cancer cells is not fully understood. Reduced WEE1 expression has been detected in breast cancer compared with normal tissues, independently of the tumor grade [21]. However, most findings suggest that both kinases act like oncogenes rather than tumor suppressors. Indeed, they are frequently overexpressed in both solid and hematological tumors and a genome-wide CRISPR screen of 563 cancer cell lines, showed that they are essential for the cell viability of almost all cell lines [30]. The dependency of cancer cells on WEE1 family proteins may be linked to the following mechanisms (Fig. 2): (i) the high proliferation rate of cancer cells that follows the activation of driver oncogenes (e.g. RAS, MYC) needs to be sustained by a strong cell cycle regulation machinery; (ii) cancer cells frequently inactivate p53, which is a key gatekeeper of G0/G1 and S phases and, as a consequence, the regulation of cell cycle is sustained entirely by the G2/M checkpoint; (iii) the over-expression of DDR-related kinases is fundamental to maintain a tolerable level of genetic instability, an intrinsic feature of cancer cells [31, 32]. Therefore, we can speculate that, once the malignant transformation process has been induced, WEE1 upregulation exerts a pro-tumorigenic functions by securing a tolerable level of genomic instability to cancer cells. The following sections summarize the current knowledge on the molecular and functional alterations of WEE1 and PKMY $\mathrm{T} 1$ in hematological and solid tumors.

\section{WEE1 and PKMYT1 genetic lesions in cancer}

WEE1 and PKMYT1 are rarely mutated in cancer patients, with an overall mutation frequency of $1.2 \%$ and $0.2 \%$, respectively (https://portal.gdc.cancer.gov). The distribution of somatic mutations is highly heterogeneous across cancer types (WEE1: 0.2-7.6\%; PKMYT1: $0.1-3.6 \%$ ), with a higher frequency in uterine corpus endometrial carcinoma (UCEC) and tumors of the gastrointestinal tract (stomach and colon adenocarcinoma, Fig. 3a, b). In particular, WEE1 mutations have 


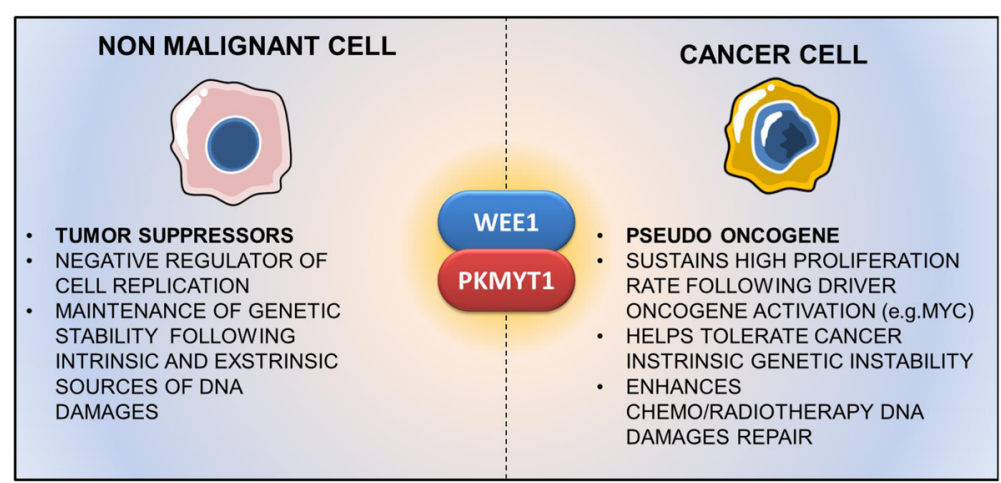

Fig. 2 WEE1 family proteins role as tumor suppressors or pseudo-oncogenes in non-malignant and cancer cells

been reported in $7.6 \%$ of UCEC cases. Moreover, PKMY $T 1$ lesions have been also detected in $2.7 \%$ of diffuse large B cell lymphoma (DLBC). Conversely, both kinase genes are rarely mutated in brain lower grade glioma (LGG), ovarian serous cystadenocarcinoma (OV), prostate adenocarcinoma (PRAD), and sarcoma (SARC), with a frequency lower than $0.5 \%$. Both genes are mainly targeted by missense mutations that preferentially cluster in the region encoding the WEE 1 kinase domain and its surroundings (Fig. 3c), suggesting a potential gain of function effect of the kinase activity. Conversely, the mutations are scattered throughout the PKMYT1 sequence (Fig. 3d). Little is known about the functional consequences of WEE1 and PKMYT1 mutations. In the majority of cancer types, the transcript expression in the mutated cases is higher than the median value of the entire cohort (https://www.cbioportal.org), supporting once more an oncogenic function. In pancreatic adenocarcinoma (PA) patients and cell lines, an insertion was identified in the WEE1 poly-T track, which contains the binding site of the HuR RNA binding protein [33]. The insertion resulted in decreased WEE1 expression upon mitomycin-induced DNA damage, which would argue against a protective effect of the mutation. Copy number alterations (CNAs) represent a more frequent event compared with mutations, with the WEE 1 gene being predominantly involved in $\mathrm{CN}$ loss $(23.7 \%$ of cases versus $7.8 \%$ of patients with $\mathrm{CN}$ gains), while PKMYT1 showing a higher percentage of $\mathrm{CN}$ gain $(15.9 \%$ versus $12.0 \%$ of $\mathrm{CN}$ loss, Fig. 3e, f). The predominance of WEE1 deletion events (6.3\% versus $3.25 \%$ of cases with amplification) was also observed in breast cancer, in line with its reduced expression, as mentioned above [21]. Overall, cancer types showing the highest recurrence (> $10 \%)$ of CNAs were OV (27.7\%), lung squamous cell carcinoma (LUSC, 14.8\%), uterine carcinosarcoma (UCS, $12.5 \%)$, and SARC (11.2\%) for WEE1 and OV (18.8\%), bladder urothelial carcinoma (BLCA, 13.7\%), and esophageal carcinoma (ESCA, 10.3\%) for PKMYT1. Of note, OV and LUSC have been classified as tumors with multiple recurrent chromosomal gains and losses [34], which may suggest a bystander effect related to chromosomal instability in these tumor types, especially in the case of WEE1 deletion, that is unexpected, based on the general oncogenic function exerted by the kinase.

\section{WEE1 and PKMYT1 functional role in hematological and solid tumors}

Few studies have analyzed WEE1 and PKMYT1 expression in hematological malignancies. Our group showed that WEE1 kinase is highly expressed in acute lymphoblastic leukemia (ALL) cell lines and primary cells in comparison with normal hematopoietic cells, and that PKMYT1 is upregulated in relapsed ALL samples compared with nonmalignant hematopoietic cells [35]. Moreover, we demonstrated that ALL cells are dependent on WEE1 functionality for their survival and proliferation and that PKMYT1 levels may influence the sensitivity to the WEE1 inhibitor AZD-1775 [35]. Similar results on the role of WEE1 were obtained in multiple myeloma (MM), acute myeloid leukemia (AML), chronic myeloid leukemia (CML), and chronic lymphocyte leukemia (CLL) [36-39]. In AML cells, WEE1 and PKMYT1 are key gene discriminating between FLT3ITD, FLT3-TKD, and NRAS-mutated samples. They were expressed at lower levels selectively in FLT3-ITD specimens in comparison with wild-type cells, suggesting either a tumor suppressor role in the leukemogenic process or a potential vulnerability $\mathrm{n}$ this AML subtype [40]. Pharmacological WEE1 inhibition alone or in combination with histone deacetylase inhibitors showed therapeutic potential in FLT3-ITD AML, confirming their dependency on WEE1 activity [41]. Since FLT3ITD AML have intrinsic homologous recombination repair defects [42]. WEE1 inhibition may exacerbate the cell genotoxic stress by disrupting multiple cell cycle checkpoints. WEE1 has been showed to be a valuable target also for lymphoma patients [43]. In parallel, 


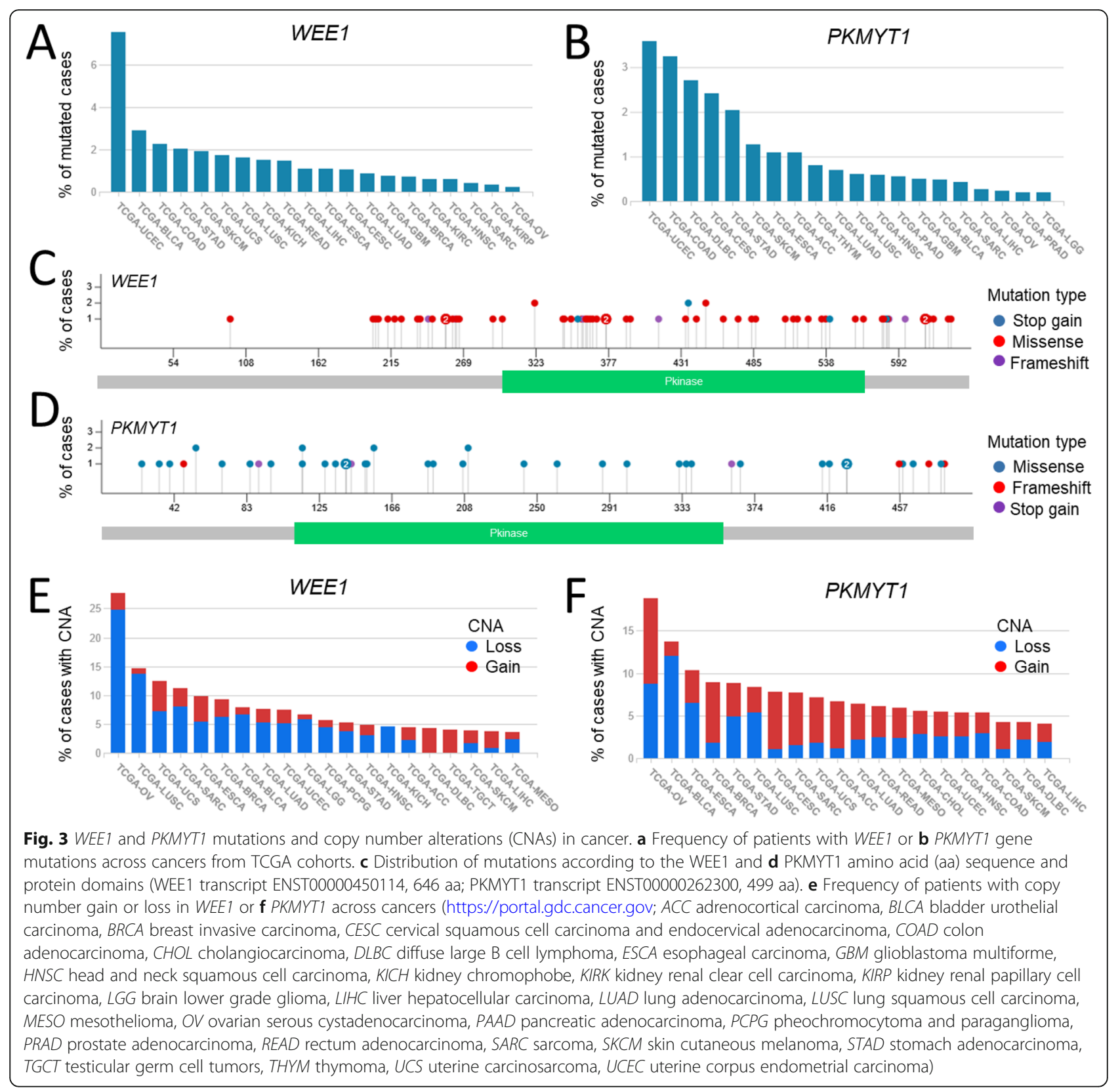

PKMYT1 proved to be essential for MM cell line viability, since its downregulation strongly decreased cell growth, while inducing apoptosis [44].

WEE1 and PKMYT1 are also over-expressed in solid tumors, including hepatocellular carcinoma, colon cancer, glioblastoma, non-small-cell lung cancer (NSCLS), neuroblastoma, and gastric cancers [31, 32, 45-47]. High WEE1 expression has been associated with negative prognostic factors including lymph node involvement, induction of metastasis, increased biomarkers of proliferation (CCND1, Ki67, or CCNA1) and resistance to treatments (radiotherapy or chemotherapy) [48-51]. Elevated PKMYT1 levels have been associated with tumor progression, a more aggressive disease, the induction of metastasis at least in NSCLS patients [45] and, generally, with poor prognosis. Depending on the cancer subtype, the expression of WEE1 and PKMYT1 has been linked with the activation of cellular pathways crucial for the specific disease. In melanoma cells, WEE1 silencing caused an increase of phospho p38 protein levels, indicating a role in the regulation of p38/MAPK pathway activation during p53independent DNA damage response [49]. In hepatocellular carcinoma and colorectal cancers, PKMYT1 regulates epithelial-mesenchymal transition (EMT), a process relevant to tumor progression, invasion, metastasis, and drug resistance, through the activation of the beta-catenin/TCF 
signaling [32, 46], while PKMYT1 has been reported to control Notch pathway in NSCLC [45]. In particular, crucial component of the pathway, including NOTCH1, p21, and HES1 are downregulated by chemical inhibition of PKMYT1 [45]. In neuroblastic tumors, PKMYT1 is required to stabilize MYCN protein, which is a crucial proto-oncogene for this cancer types [52]. Moreover, in esophageal squamous cell carcinoma (ESCC) cell lines and primary cells, the expression of PKMYT1 is associated with and regulates the activation of the AKY/mTOR pathway [53] (Table 1). Taken together, this evidence suggests a broad role of WEE1/PKMYT1 besides the DNA damage response pathway that may increase the interest towards its therapeutic targeting.

\section{Development of WEE1 and PKMYT1 inhibitors WEE1 and PKMYT1 inhibitors have single agent and chemo-sensitizer effects}

Due to their potential oncogenic role, WEE1 and PKMY T1 have been investigated as therapeutic targets for hematological and solid tumors. Several pharmacological inhibitors have been designed and subsequently validated in different cancer models. The available literature highlights a common mechanism of action of WEE1/ PKMYT1 inhibitors in cancer cells either in single agent or in combination with DNA damaging agents (chemotherapy/radiotherapy). WEE1/PKMYT1 kinase inhibition causes $\mathrm{G} 2 / \mathrm{M}$ cell cycle checkpoint override, premature mitotic entry, and cell death during mitosis, through a mechanism generally known as mitotic catastrophe (Fig. 4a). From a biological point of view, the inhibition of WEE1 kinase causes a significant reduction of phosphoCDK1 (Tyr15), thus promoting the accumulation of active CDK1-cyclin B1 complex and, consequently, mitotic entry.
The beginning of mitosis is also associated with a progressive accumulation of DNA damages and the degeneration in mitotic catastrophe. The sensitivity to WEE1 kinase inhibitors in relation to TP53 mutational status remains controversial. Indeed, some studies reported increased sensitivity of TP53 mutant cell lines to WEE1 inhibitors in comparison to TP53 wild-type ones [62, 63], while others showed no association between p53 functionality and the effectiveness of WEE1 inhibition [35, 64]. These discrepancies may be linked to the intrinsic chromosomal instability of the analyzed tumors and to additional alterations deregulating the G1 checkpoint in TP53 wild-type cases that may enhance the sensitivity to WEE1 targeting.

Regarding the role of WEE1 inhibitors as chemosensitizer agents, a large number of studies demonstrated a synergistic activity between DNA damaging agents (chemotherapy including doxorubicin, cytarabine, methotrexate, cisplatin, clofarabine, etoposide, 5-fluorouracil, and radiotherapy) and different WEE1/PKMYT1 inhibitors in preclinical models $[48,56,65-69]$. The mechanism of action of the combination is based on the inhibition of the DDR pathway following induction of DNA damage induced by the chemotherapy or radiotherapy agents. In this scenario, cancer cells with damaged DNA fail to arrest cell cycle, continue to proliferate, and accumulate massive DNA damage until a point of no return (Fig. 4b). Indeed, several DNA damaging agent promote the indirect activation of WEE1 and PKMYT1 kinases, as showed mostly by the activation of cell cycle checkpoints ( $\mathrm{S}$ and G2/M checkpoints) in cancer cells. We summarized in Table 2 the results of preclinical studies in which the effect of different chemotherapy agents or radiotherapy has been evaluated in terms of cell cycle perturbation and altered expression of WEE1 or PKMYT1 following in vitro or

Table 1 WEE1 and PKMYT1 molecular alterations in hematological and solid tumors according to literature

\begin{tabular}{|c|c|c|c|c|}
\hline Gene & Genetic alteration & Disease & Effect/prognostic value & Reference \\
\hline \multicolumn{5}{|c|}{ Hematological tumors } \\
\hline \multirow[t]{2}{*}{ WEE1 } & Over-expression & $\begin{array}{l}\text { ALL; AML; MM; CML; } \\
\text { CLL; DLBCL }\end{array}$ & Crucial for cell viability of cancer cells (experimentally proven). & {$[35-40,43,54]$} \\
\hline & Copy number Gain & AML & Biological effect or prognostic value unknown & [55] \\
\hline PKMYT1 & Over-expression & $A L L ; M M$ & Crucial for cell viability of cancer cells (experimentally proven). & {$[35,44]$} \\
\hline \multicolumn{5}{|c|}{ Solid tumors } \\
\hline \multirow[t]{2}{*}{ WEE1 } & Over-expression & GC; MaM; GL; OC; CC & $\begin{array}{l}\text { Associated with lymph node involvement, induction of } \\
\text { metastasis, increased biomarkers of proliferation (CCND1, Ki67 } \\
\text { or CCNA1), resistance to treatment and poor overall survival. }\end{array}$ & {$[48-51,56-60]$} \\
\hline & Mutation & PA & $\begin{array}{l}\text { Insertion causing decrease WEE1 expression upon DNA } \\
\text { damage }\end{array}$ & [33] \\
\hline \multirow[t]{2}{*}{ PKMYT1 } & Over-expression & $\mathrm{HC} ; \mathrm{CC} ; \mathrm{GLB} ; \mathrm{NSCLC} ; \mathrm{N} ; \mathrm{GS}$ & $\begin{array}{l}\text { Associated with tumor progression, aggressive disease and } \\
\text { poor overall survival. }\end{array}$ & {$[31,32,45-47]$} \\
\hline & Mutation & $\mathrm{N}$ & Biological effect or prognostic value unknown & [61] \\
\hline
\end{tabular}

ALL acute lymphoblastic leukemia, $A M L$ acute myeloid leukemia, $M M$ multiple myeloma, $C M L$ chronic myeloid leukemia, $C L L$ chronic lymphocyte leukemia, $D L B C L$ diffuse large B cell lymphoma, GC gastric cancer, MaM malignant melanoma, GL gliomas, OC ovarian cancer, CC colorectal cancer, PA pancreatic adenocarcinoma, $H C$ hepatocellular carcinoma, GLB glioblastoma, NSCLC non-small-cell lung cancer, N neuroblastoma 


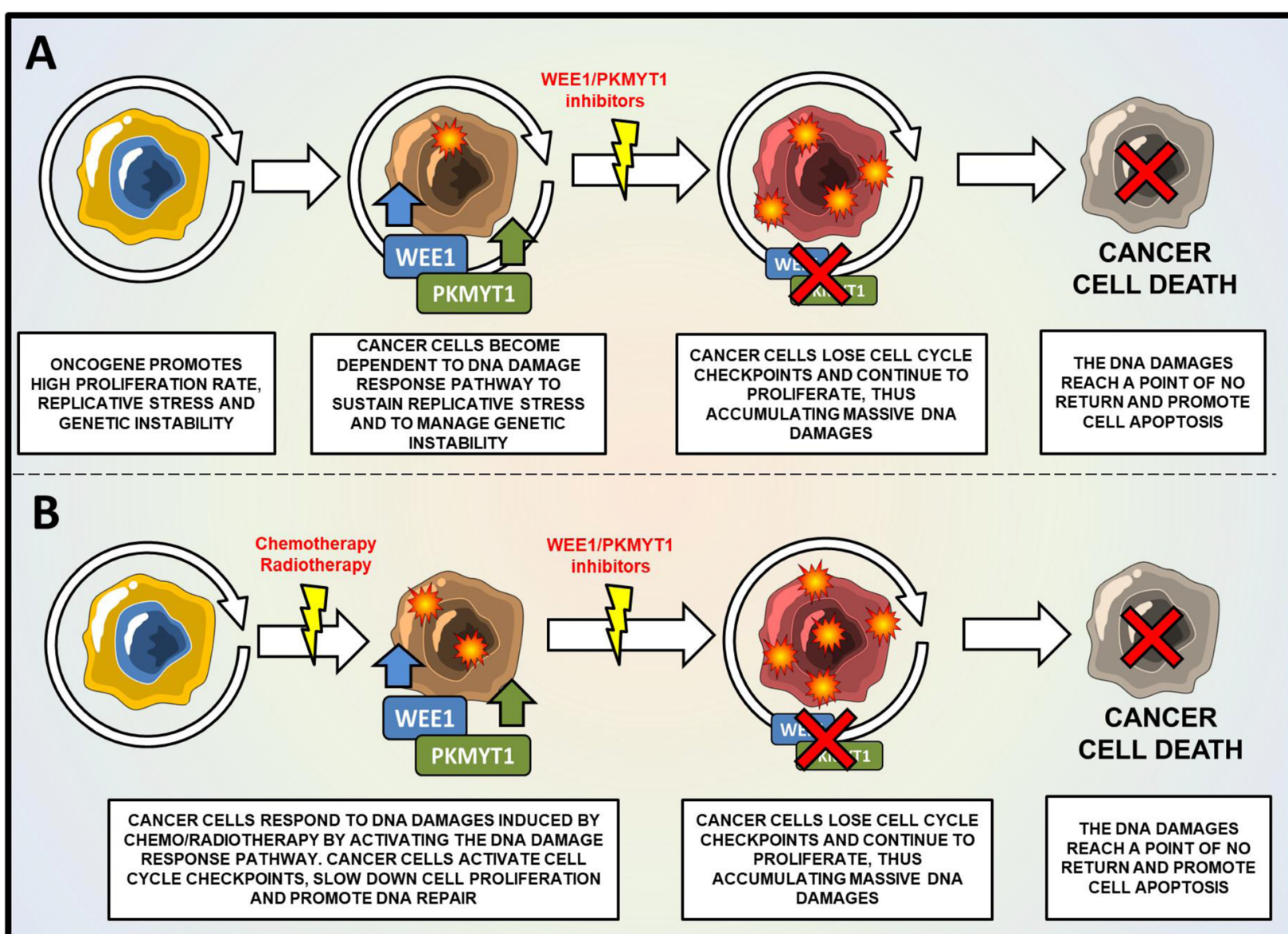

Fig. 4 Mechanism of action of WEE1/PKMYT1 inhibitors for the treatment of cancer cells. a Schematic representation of WEE1/PKMYT1 inhibition as monotherapy. In cancer cells, oncogenes promote high rate of proliferation, replication stress and the over-expression of WEE1/PKMYT1 kinases. In this scenario, cancer cells need WEE1 and PKMYT1 to sustain replication stress and proliferation. The inhibition of WEE1/PKMYT1 results in the accumulation of DNA damages, the increase of genetic instability and induction of apoptosis. $\mathbf{b}$ Schematic representation of WEE1/PKMYT1 inhibition in combination with DNA damaging agents. Cancer cells respond to DNA damages by activating WEE1/PKMYT1 kinases. The inhibition of WEE1/PKMYT1 enhances the cytotoxicity of DNA damaging agents by inhibiting DNA repair and promoting cell cycle progression even in the presence of DNA damages. Therefore, cancer cells accumulate massive DNA damages until a point of no return

in vivo treatment. Taken together, the abovementioned data prove that WEE1 and PKYMYT1 are ideal targets to override cell cycle checkpoint regulation and to improve the efficacy of DNA-damaging agents. In particular, tumors with a high level of chromosomal instability may respond to WEE1/PKMYT1 inhibition per se, while cases with a more stable genomic asset may benefit of the combination between DNA-damaging agents and WEE1 family kinase inhibitors. The following sections reports the main preclinical and clinical findings obtained using small molecules inhibitors of WEE1 and PKMYT1 kinases.

\section{Preclinical studies of WEE1 and PKMYT1 inhibitors}

Several targeted compounds showed an inhibitory activity on WEE1 and PKMYT1 kinases and their efficacy was proven in a number of tumor types. Table 3 shows the main preclinical studies that used WEE1/PKMYT1 inhibitors in single agent or in combination with chemo/ radiotherapy agents in different tumor types.

PD0166285 is the first reported drug, with an inhibitory activity against WEE1, PKMYT1, and a range of other kinases including c-Src, EGFR, FGFR1, CHK1, and PDGFRb [151].

Adavosertib (AZD-1775) is the first highly potent and selective WEE1 inhibitor. A large number of preclinical studies evaluated its efficacy in single agent and in combinatory approaches. Regarding the mechanism of action, adavosertib induces $\mathrm{S}$ and/or G2/M cell cycle checkpoints override, depending on cancer types, when used in monotherapy. Cell cycle perturbation is associated with a progressive accumulation of DNA damages and by the induction of apoptosis [35, 99, 119-122]. This last event is cell cycle phase-dependent and can occur (i) as a consequence of $\mathrm{S}$ phase checkpoint 
Table 2 Effects of standard of care chemo/radiotherapy agents on cell cycle checkpoints activation

\begin{tabular}{|c|c|c|c|}
\hline Chemotherapy agents/radiotherapy & Intra S checkpoint & G2/M checkpoint & $\begin{array}{l}\text { WEE1 and/or PKMYT1 experimentally } \\
\text { proven involvement in cancer model }\end{array}$ \\
\hline Actinomycin & No & Yes $[70,71]$ & WEE1 upregulation [71] \\
\hline Azacitidine & No & Yes [72] & NA \\
\hline Bleomycin & No & Yes [73] & NA \\
\hline Carboplatin & No & Yes [74] & NA \\
\hline Cisplatin & No & Yes $[75,76]$ & WEE1 inhibition enhanced cytotoxicity $[76,77]$ \\
\hline Cyclophosphamide & NA & NA & WEE1 upregulation [78] \\
\hline Cytarabine & Yes $[79,80]$ & Yes $[79,80]$ & WEE1 upregulation $[38,81]$ \\
\hline Clofarabine & Yes [35] & No & WEE1 inhibition enhanced cytotoxicity [35] \\
\hline Daunorubicin & Yes [82] & Yes [82] & NA \\
\hline Decitabine & No & Yes [83] & NA \\
\hline Docetaxel & No & Yes $[84,85]$ & NA \\
\hline Doxorubicin & No & Yes [86] & $\begin{array}{l}\text { WEE1 upregulation [86]; WEE1 inhibition } \\
\text { enhanced cytotoxicity [35] }\end{array}$ \\
\hline Epirubicin & No & Yes $[87,88]$ & WEE1 inhibition enhanced cytotoxicity [89] \\
\hline Epothilone & No & Yes [90] & NA \\
\hline Etoposide & No & Yes [91] & WEE1 inhibition enhanced cytotoxicity [67] \\
\hline Fluorouracil & Yes [92] & No & WEE1 inhibition enhanced cytotoxicity [92] \\
\hline Fludarabine & Yes [80] & No & NA \\
\hline Gemcitabine & Yes [80] & No & $\begin{array}{l}\text { WEE1 upregulation [93]; WEE1 inhibition } \\
\text { enhanced cytotoxicity [94] }\end{array}$ \\
\hline Hydroxyurea & Yes [95] & No & WEE1 inhibition enhanced cytotoxicity [96] \\
\hline Idarubicin & No & Yes [97] & NA \\
\hline Irinotecan & No & Yes [98] & WEE1 inhibition enhanced cytotoxicity [99] \\
\hline Mechlorethamine & Yes [100] & Yes [100] & NA \\
\hline Mercaptopurine & Yes [101] & No & NA \\
\hline Methotrexate & Yes [102] & No & WEE1 inhibition enhanced cytotoxicity [103] \\
\hline Mitoxantrone & No & Yes [104] & WEE1 inhibition enhanced cytotoxicity [78] \\
\hline Oxaliplatin & No & Yes [105] & WEE1 inhibition enhanced cytotoxicity [106] \\
\hline Paclitaxel & No & Yes [107] & WEE1 inhibition enhanced cytotoxicity [108] \\
\hline Pemetrexed & Yes [109] & No & WEE1 inhibition enhanced cytotoxicity [110] \\
\hline Radiotherapy (ionizing radiation) & No & Yes [111] & WEE1 inhibition enhanced cytotoxicity [68] \\
\hline Teniposide & Yes [112] & Yes [112] & NA \\
\hline Thioguanine & Yes [113] & Yes [113] & WEE1 inhibition enhanced cytotoxicity [65] \\
\hline Topotecan & No & Yes [114] & WEE1 inhibition enhanced cytotoxicity [115] \\
\hline Vinblastine & No & Yes [116] & NA \\
\hline Vincristine & No & Yes [117] & WEE1 inhibition enhanced cytotoxicity [118] \\
\hline
\end{tabular}

override, when cancer cells start DNA replication even in the presence of DNA damages (replicative catastrophe); (ii) following G2/M phase checkpoint override, that results in forced entry into mitosis, even in the presence of DNA damages (mitotic catastrophe).

In combination strategies, adavosertib was able to enhance the cytotoxicity of chemo/radiotherapy agents, by inducing cell cycle checkpoint override, inhibition of
DNA damage repair, and induction of apoptosis [35, 37, 38, 92, 121, 127-129]. The chemo-sensitizer efficacy of DDR inhibitors has been linked to drug scheduling [94, 152, 153]. Recently in pancreatic adenocarcinoma cells, it has been reported that the efficacy of a triple regimen combining gemcitabine, CHK1, and WEE1 inhibitors is strictly dependent on the timing of drug administration. Indeed, the maximum effect of the combination is 
Table 3 Preclinical studies evaluating the effect of WEE1 inhibitors in monotherapy or in combination with chemotherapy/ radiotherapy in cancer

\begin{tabular}{|c|c|c|c|c|}
\hline Inhibitor & Treatment & Cancer model & Main biological effect & References \\
\hline PD0166285 & M & GBM-astrocytoma & $\begin{array}{l}\text {-G2/M checkpoint override } \\
\text {-Forced mitotic entry }\end{array}$ & [51] \\
\hline Adavosertib & M & MM, ALL, AML TNBC, DLBCL, MCL & $\begin{array}{l}\text {-G2/M checkpoint override } \\
\text {-Forced mitotic entry } \\
\text {-Mitotic catastrophe } \\
\text {-Replicative catastrophe }\end{array}$ & {$[35,99,119-122]$} \\
\hline PD0166285 & $+R$ & GBM-astrocytoma & $\begin{array}{l}\text {-Mitotic catastrophe } \\
\text {-Inhibition of DNA repair }\end{array}$ & [51] \\
\hline Adavosertib & $+R$ & $C C, L C, B C, P C, O C, D L B C L, E S$ & $\begin{array}{l}\text {-Increased DNA damage } \\
\text {-Induction of apoptosis } \\
\text {-Mitotic catastrophe }\end{array}$ & {$[78,99,123-126]$} \\
\hline Adavosertib & $+\mathrm{C}$ & $\mathrm{AML}, \mathrm{ALL}, \mathrm{MM}, \mathrm{BC}, \mathrm{CC}, \mathrm{GC}, \mathrm{DLBCL}$ & $\begin{array}{l}\text {-S or G2/M checkpoint override } \\
\text {-Increased DNA damaged } \\
\text {-Induction of apoptosis }\end{array}$ & $\begin{array}{l}{[35,37,38,76,92,99,} \\
121,127-129]\end{array}$ \\
\hline Adavosertib & $+\mathrm{HDAC}$ i & AML, HNSCC & $\begin{array}{l}\text {-Replication stress } \\
\text {-Replicative catastrophe } \\
\text {-Increased DNA damage } \\
\text {-Inhibition of DNA repair }\end{array}$ & {$[41,130,131]$} \\
\hline Adavosertib & + ATR i & $\mathrm{AML}, \mathrm{DLBCL}, \mathrm{MCL}, \mathrm{BC}$ & $\begin{array}{l}\text {-Replication stress } \\
\text {-Replicative catastrophe } \\
\text {-Increased DNA damaged } \\
\text {-Inhibition of DNA repair }\end{array}$ & [132-135] \\
\hline Adavosertib & + mTOR i & AML, ALL, OC, NSCLC & -Inhibition of DNA repair & [136-139] \\
\hline Adavosertib & $+\mathrm{CHK} 1 \mathrm{i}$ & $M C L, D L B C L, A L L, A M L$ & $\begin{array}{l}\text {-Replication stress } \\
\text {-Increased DNA damage } \\
\text {-Replicative catastrophe }\end{array}$ & {$[103,140-142]$} \\
\hline Adavosertib & $+B C L 2 i / M C L-1$ i & DLBCL & $\begin{array}{l}\text {-Force mitotic entry } \\
\text {-Increase DNA damage } \\
\text {-INDUCTION of apoptosis }\end{array}$ & [143] \\
\hline Adavosertib & +PARP1 i & NSCLC, AML, ALL & $\begin{array}{l}\text {-G2/M checkpoint override } \\
\text {-Replication stress } \\
\text {-Increased DNA damage } \\
\text {-Inhibition of DNA repair }\end{array}$ & {$[126,144-146]$} \\
\hline Adavosertib & + AURORA A i & HNSCC & $\begin{array}{l}\text {-Forced mitotic entry } \\
\text {-Mitotic catastrophe }\end{array}$ & [147] \\
\hline Adavosertib & + CDK2 i & BC & $\begin{array}{l}\text {-Replication stress } \\
\text {-Replicative catastrophe }\end{array}$ & [89] \\
\hline Adavosertib & +SIRT1 i & LC & -Inhibition of DNA repair & [148] \\
\hline Adavosertib & $+C D K 4-6$ i & S & -Replication stress & [149] \\
\hline Adavosertib & +BCR-ABL1 i & ALL & $\begin{array}{l}\text {-Inhibition of DNA repair -G2/M } \\
\text { checkpoint override }\end{array}$ & [35] \\
\hline Adavosertib & +Proteasome i & MM & $\begin{array}{l}\text {-G2/M checkpoint override } \\
\text {-Forced mitotic entry } \\
\text {-Inhibition of DNA repair }\end{array}$ & [36] \\
\hline Adavosertib & $+\mathrm{BET} \mathrm{i}$ & NSCLC & $\begin{array}{l}\text {-Inhibition of DNA repair } \\
\text {-Forced mitotic entry } \\
\text {-Mitotic catastrophe }\end{array}$ & [150] \\
\hline
\end{tabular}

$M$ monotherapy, $R$ radiotherapy, $C$ chemotherapy, $A L L$ acute lymphoblastic leukemia, $A M L$ acute myeloid leukemia, $M M$ multiple myeloma, $D L B C L$ diffuse large $B$ cell lymphoma, $M C L$ mantle cell lymphoma, GC gastric cancer, GL gliomas, OC ovarian cancer, CC colorectal cancer, $P C$ pancreatic cancer, ES esophageal cancer, $H C$ hepatocellular carcinoma, GLB glioblastoma, NSCLC non-small-cell lung cancer, $N$ neuroblastoma, $S$ sarcomas, $L C$ lung cancer, BC breast cancer, HNSCC head and neck squamous cell carcinoma, TNBC triple negative breast cancer

obtained when gemcitabine and CHK1 inhibitors are administered simultaneously (thus inducing replicative stress) and adavosertib is added at a later time [94].
Moreover, strong synergism has been observed by combining adavosertib with small molecules, including DDR-related inhibitors (CDK2 [89], CDK4-6 [149], 
CHK1 [103, 140-142], ATM [132-135], AURORA A [147], PARP1 [144], SIRT1 [148] inhibitors), histone deacetylase (HDAC) inhibitors [41, 130, 131], tyrosine kinase inhibitors (BCR-ABL1 inhibitors [35]), antiapoptotic protein inhibitors (BCL2 and MCL1 inhibitors [143]), mTOR inhibitor [136-139], and proteasome inhibitors [36].

We have recently reported synergistic effects of adavosertib in combination with different tyrosine kinase inhibitors in both BCR-ABL1-positive and -negative ALL cell lines and primary cells. Interestingly, strong synergism was found in $B C R-A B L 1$-negative ALL cell lines treated with adavosertib in combination with bosutinib isomer. In the study, we speculated that the strong cytotoxic effect of the combination was due to the concomitant inhibition of WEE1 and PKMYT1 kinases [35]. Indeed, no selective inhibitor has been currently developed to target its functionality. However, several known tyrosine kinase inhibitors have an inhibitory off-target effect on PKMYT1. Among them, compounds commonly used for the treatment of $B C R-A B L 1$-positive CML and ALL, as dasatinib and bosutinib (and a structural isomer of bosutinib $[154,155]$ ) were shown to inhibit PKMYT1 activity.

Overall, the data suggest that WEE1/PKMYT1 inhibition is a suitable pharmacological target for combination strategies in cancer. The broad spectrum of activities exerted by the two kinases, and especially by WEE1, across the cell cycle, makes them good candidates for a number of diverse therapeutic combinations.

\section{WEE1 inhibitors from bench to bedside}

Several clinical studies are currently evaluating the efficacy of adavosertib on different aggressive and advanced tumors (Table 4).

The results of phase I trials showed that adavosertib is well tolerated both in single agent and in combination. Depending on the study, the maximum tolerated dose (MTD) was established between 150 and $225 \mathrm{mg}$ orally twice per day for 2.5 days per 2 weeks [156-158]. The most common adverse events reported in the abovementioned studies were fatigue, nausea, vomiting, diarrhea, and hematologic toxicity. Moreover, correlative studies performed on tumor biopsies confirmed in vivo the mechanism of action of adavosertib. Indeed, immunohistochemistry analyses showed a reduction of phospho-CDK1 (Tyr15) and an increase of DNA damages (phospho$\gamma \mathrm{H} 2 \mathrm{AX})$ in cancer cells $[156,157]$.

The phase II studies confirmed that adavosertib sensitizes cancer patients to different chemotherapy agents. Interestingly, adavosertib showed efficacy when combined with carboplatin in TP53-mutated ovarian cancer patients, refractory or resistant to first-line platinumbased chemotherapy [159]. Similar results were reported in platinum-resistant primary ovarian cancer patients after treatment with the combination of adavosertib and a single chemotherapeutic agent (carboplatin, paclitaxel, gemcitabine, or pegylated liposomal doxorubicin) [160].

\section{Primary resistance and predictive markers of response to WEE1/PKMYT1 based therapies}

Several DDR inhibitors have proved their efficacy against different cancer types in the preclinical and clinical settings [161-165]. Among them, WEE1 inhibitor seems to be the most effective ones, also favored by a relative low off-target toxicity. However, despite the number of studies and the promising results, few predictive markers of response have been identified. Recently, cyclin E level has been linked to the efficacy of adavosertib in breast cancer models [89], with cyclin E-high cells, that generally show elevated chromosome instability, being more sensitive compared with cyclin E-low ones. Despite the reported low levels of WEE1 expression in breast cancer, chromosome instability, that has also prognostic potential mainly in grade 2 tumors [89], may explain the effectiveness of WEE1 inhibitors, as supported by the predictive role of cyclin E. Our group and others showed that high PKMYT1 expression associates with reduced sensitivity to adavosertib, indicating a potential compensatory effect $[35,166]$. Moreover, high-throughput proteomic profiling demonstrated that small cell lung cancer and ovarian cancer models with primary resistance to adavosertib express high levels of AKT/mTOR pathway molecules and phosphorylated S6 ribosomal protein $[137,138]$. In acute leukemia models, the sensitivity to adavosertib has been recently linked to HDAC and MYC regulation. Indeed, by generating adavosertibresistant models, the researchers found that resistant acute leukemia cell lines are dependent on increased HDAC activity for their survival, partly due to increased KDM5A function. In addition, gene expression analyses demonstrated a HDAC-dependent expression of MYC in the adavosertib-resistant cell lines [167]. These observations support the success of preclinical studies combining WEE1 and HDAC [41, 130, 131] or bromodomain inhibitors [150].

\section{Conclusion}

Thanks to a constantly growing amount of preclinical and clinical data, our knowledge on cancer biology is increasing and, consequently, the list of cancer hallmarks has been progressively expanding. Recent findings demonstrated that cancer cells are characterized by functional and molecular alterations in crucial genes involved in the DDR pathway, which is fundamental for cell cycle regulation, DNA damages recognition, and repair. Functional alterations of DDRgene have a deep impact on tumor progression and on the clinical outcome of cancer patients. Indeed, the efficacy of 
Table 4 Clinical trials evaluating WEE1/PKMYT1 inhibitor in monotherapy or in combination for cancer therapy

\begin{tabular}{|c|c|c|c|c|c|}
\hline Study ID & Study title & Tumor & Interventions & Status & Phase \\
\hline NCT02610075 & $\begin{array}{l}\text { Phase Ib Study to Determine MTD of AZD1775 Monotherapy in } \\
\text { Patients With Locally Advanced or Metastatic Solid Tumours. }\end{array}$ & S & AZD1775 & C & 1 \\
\hline NCT03668340 & $\begin{array}{l}\text { AZD1775 in Women With Recurrent or Persistent Uterine } \\
\text { Serous Carcinoma }\end{array}$ & S & AZD1775 & $\mathrm{R}$ & 2 \\
\hline NCT02482311 & $\begin{array}{l}\text { Safety, Tolerance, PK, and Anti-tumour Activity of AZD1775 } \\
\text { Monotherapy in Patients With Advanced Solid Tumours }\end{array}$ & S & AZD 1775 & C & 1 \\
\hline NCT02207010 & A Phase 0 Study of AZD1775 in Recurrent GBM Patients & S & AZD1775 & NA & 1 \\
\hline NCT03315091 & $\begin{array}{l}\text { Phase I Study to Assess the Effect of Food on AZD1775 } \\
\text { Pharmacokinetics in Patients With Advanced Solid Tumours }\end{array}$ & S & AZD1775 & C & 1 \\
\hline NCT01748825 & AZD1775 for Advanced Solid Tumors & $\mathrm{S} / \mathrm{H}$ & AZD1775 & ANR & 1 \\
\hline NCT02511795 & $\begin{array}{l}\text { AZD1775 Combined With Olaparib in Patients With Refractory } \\
\text { Solid Tumors }\end{array}$ & S & AZD1775 + Olaparib & C & 1 \\
\hline NCT03313557 & $\begin{array}{l}\text { AZD } 1775 \text { Continued Access Study to Assess Safety and } \\
\text { Tolerability for Patients Enrolled in AZD1775 Clinical } \\
\text { Pharmacology Studies }\end{array}$ & S & AZD1775 & C & 1 \\
\hline NCT02593019 & $\begin{array}{l}\text { Phase II, Single-arm Study of AZD1775 Monotherapy in } \\
\text { Relapsed Small Cell Lung Cancer Patients }\end{array}$ & $S$ & AZD1775 & NA & 2 \\
\hline NCT02688907 & $\begin{array}{l}\text { Phase II, Single-arm Study of AZD1775 Monotherapy in Relapsed } \\
\text { Small Cell Lung Cancer Patients With MYC Family Amplification } \\
\text { or CDKN2A Mutation Combined With TP53 Mutation }\end{array}$ & S & AZD1775 & $\mathrm{T}$ & 2 \\
\hline NCT02087176 & $\begin{array}{l}\text { A Placebo Controlled Study Comparing AZD } 1775 \text { + Docetaxel } \\
\text { Versus Placebo + Docetaxel to Treat Lung Cancer }\end{array}$ & S & AZD1775 + Docetaxel & $\mathrm{T}$ & 2 \\
\hline NCT03012477 & CISPLATIN + AZD-1775 In Breast Cancer & S & AZD1775 + Cisplatin & ANR & 2 \\
\hline NCT02341456 & $\begin{array}{l}\text { Phase Ib Study AZD } 1775 \text { in Combination With Carboplatin and } \\
\text { Paclitaxel in Adult Asian Patients With Solid Tumours }\end{array}$ & S & $\begin{array}{l}\text { AZD } 1775+\text { Carboplatin } \\
\text { or Paclitaxel }\end{array}$ & C & 1 \\
\hline NCT02791919 & $\begin{array}{l}\text { Wee1 Kinase Inhibitor AZD } 1775 \text { and Combination Chemotherapy } \\
\text { in Treating Children, Adolescents and Young Adults With } \\
\text { Relapsed or Refractory Acute Myeloid Leukemia }\end{array}$ & $\mathrm{H}$ & $\begin{array}{l}\text { AZD } 1775+\text { Cytarabine } \\
\text { or Filgrastim } \\
\text { or Fludarabine Phosphate }\end{array}$ & W & 1 \\
\hline NCT02513563 & AZD1775 Plus Carboplatin-Paclitaxel in Squamous Cell Lung Cancer & S & $\begin{array}{l}\text { AZD } 1775+\text { Carboplatin } \\
\text { or Paclitaxel }\end{array}$ & $\mathrm{R}$ & 2 \\
\hline NCT03718143 & $\begin{array}{l}\text { AZD1775 in Advanced Acute Myeloid Leukemia, Myelodysplastic } \\
\text { Syndrome and Myelofibrosis }\end{array}$ & $\mathrm{H}$ & AZD1775 + Cytarabine & $\mathrm{T}$ & 2 \\
\hline NCT02585973 & $\begin{array}{l}\text { Dose-escalating AZD } 1775 \text { + Concurrent Radiation + Cisplatin for } \\
\text { Intermediate/High Risk HNSCC }\end{array}$ & S & $\begin{array}{l}\text { AZD1775 + Cisplatin + } \\
\text { Radiation }\end{array}$ & $\mathrm{R}$ & 1 \\
\hline NCT02087241 & $\begin{array}{l}\text { Ph II Trial of Carboplatin and Pemetrexed With or Without } \\
\text { AZD1775 for Untreated Lung Cancer }\end{array}$ & S & $\begin{array}{l}\text { AZD } 1775+\text { pemetrexed } \\
\text { or carboplatin }\end{array}$ & $\mathrm{T}$ & 2 \\
\hline NCT02381548 & $\begin{array}{l}\text { Phase I Trial of AZD } 1775 \text { and Belinostat in Treating Patients With } \\
\text { Relapsed or Refractory Myeloid Malignancies or Untreated Acute } \\
\text { Myeloid Leukemia }\end{array}$ & $\mathrm{H}$ & AZD1775 + Belinostat & $\mathrm{T}$ & 1 \\
\hline NCT03333824 & $\begin{array}{l}\text { Effects of AZD1775 on the PK Substrates for CYP3A, CYP2C19, } \\
\text { CYP1A2 and on QT Interval in Patients With Advanced Cancer }\end{array}$ & S & AZD1775 & C & 1 \\
\hline NCT02906059 & $\begin{array}{l}\text { Study of Irinotecan and AZD1775, a Selective Wee } 1 \text { Inhibitor, in } \\
\text { RAS or BRAF Mutated, Second-line Metastatic Colorectal Cancer }\end{array}$ & S & AZD1775 + Irinotecan & $\mathrm{R}$ & 1 \\
\hline NCT02037230 & $\begin{array}{l}\text { Dose Escalation Trial of AZD1775 and Gemcitabine (+Radiation) } \\
\text { for Unresectable Adenocarcinoma of the Pancreas }\end{array}$ & S & $\begin{array}{l}\text { AZD } 1775+\text { Gemcitabine+ } \\
\text { Radiation Therapy }\end{array}$ & C & 1,2 \\
\hline NCT02617277 & $\begin{array}{l}\text { Safety, Tolerability and Pharmacokinetics of AZD } 1775 \\
\text { (Adavosertib) Plus MEDI } 4736 \text { (Durvalumab) in Patients With } \\
\text { Advanced Solid Tumours }\end{array}$ & S & AZD1775 + Durvalumab & ANR & 1 \\
\hline NCT02666950 & $\begin{array}{l}\text { WEE1 Inhibitor AZD1775 With or Without Cytarabine in Treating } \\
\text { Patients With Advanced Acute Myeloid Leukemia or } \\
\text { Myelodysplastic Syndrome }\end{array}$ & $\mathrm{H}$ & AZD1775 + Cytarabine & C & 2 \\
\hline NCT01047007 & $\begin{array}{l}\text { A Dose Escalation Study of MK1775 in Combination With 5-FU or } \\
\text { 5-FU/CDDP in Patients With Advanced Solid Tumor (1775-005) }\end{array}$ & S & $\begin{array}{l}\text { AZD } 1775+5 \text {-FU or } \\
\text { 5-FU/CDDP }\end{array}$ & $\mathrm{T}$ & 1 \\
\hline NCT01164995 & Study With Wee-1 Inhibitor MK-1775 and Carboplatin to Treat & S & AZD1775 + carboplatin & NA & 2 \\
\hline
\end{tabular}


Table 4 Clinical trials evaluating WEE1/PKMYT1 inhibitor in monotherapy or in combination for cancer therapy (Continued)

\begin{tabular}{|c|c|c|c|c|c|}
\hline Study ID & Study title & Tumor & Interventions & Status & Phase \\
\hline & p53 Mutated Refractory and Resistant Ovarian Cancer & & & & \\
\hline NCT02448329 & $\begin{array}{l}\text { Study of AZD1775 in Combination With Paclitaxel, in Advanced } \\
\text { Gastric Adenocarcinoma Patients Harboring TP53 Mutation as a } \\
\text { Second-line Chemotherapy }\end{array}$ & S & AZD1775 + paclitaxel & $\mathrm{R}$ & 2 \\
\hline NCT02508246 & $\begin{array}{l}\text { WEE1 Inhibitor MK-1775, Docetaxel, and Cisplatin Before Surgery } \\
\text { in Treating Patients With Borderline Resectable Stage III-IVB } \\
\text { Squamous Cell Carcinoma of the Head and Neck }\end{array}$ & S & $\begin{array}{l}\text { AZD } 1775+\text { Cisplatin }+ \\
\text { Docetaxel }\end{array}$ & C & 1 \\
\hline NCT03253679 & $\begin{array}{l}\text { AZD1775 in Treating Patients With Advanced Refractory Solid } \\
\text { Tumors With CCNE1 Amplification }\end{array}$ & S & AZD1775 & $\mathrm{R}$ & 2 \\
\hline NCT01076400 & $\begin{array}{l}\text { A Study of MK-1775 in Combination With Topotecan/Cisplatin in } \\
\text { Participants With Cervical Cancer (MK-1775-008) }\end{array}$ & S & $\begin{array}{l}\text { AZD1775 + Topotecan or } \\
\text { Cisplatin }\end{array}$ & T & 1,2 \\
\hline NCT02196168 & $\begin{array}{l}\text { Cisplatin With or Without WEE1 Inhibitor MK-1775 in Treating } \\
\text { Patients With Recurrent or Metastatic Head and Neck Cancer }\end{array}$ & S & AZD1775 +Cisplatin & $\mathrm{T}$ & 2 \\
\hline NCT02101775 & $\begin{array}{l}\text { Gemcitabine Hydrochloride With or Without WEE1 Inhibitor MK- } \\
1775 \text { in Treating Patients With Recurrent Ovarian, Primary } \\
\text { Peritoneal, or Fallopian Tube Cancer }\end{array}$ & S & AZD1775 + Gemcitabine & ANR & 2 \\
\hline NCT03028766 & $\begin{array}{l}\text { WEE1 Inhibitor With Cisplatin and Radiotherapy: A Trial in Head } \\
\text { and Neck Cancer }\end{array}$ & S & $\begin{array}{l}\text { AZD } 1775+\text { Cisplatin + } \\
\text { Radio therapy }\end{array}$ & ANR & 1 \\
\hline NCT01357161 & $\begin{array}{l}\text { A Study of MK-1775 in Combination With Paclitaxel and } \\
\text { Carboplatin Versus Paclitaxel and Carboplatin Alone for } \\
\text { Participants With Platinum-Sensitive Ovarian Tumors With the } \\
\text { P53 Gene Mutation (MK-1775-004) }\end{array}$ & S & $\begin{array}{l}\text { AZD } 1775+\text { paclitaxel + } \\
\text { carboplation }\end{array}$ & C & 2 \\
\hline NCT03284385 & $\begin{array}{l}\text { Testing AZD1775 in Advanced Solid Tumors That Have a } \\
\text { Mutation Called SETD2 }\end{array}$ & S & AZD1775 & $\mathrm{R}$ & 2 \\
\hline NCT00648648 & $\begin{array}{l}\text { A Dose Escalation Study of MK-1775 in Combination With Either } \\
\text { Gemcitabine, Cisplatin, or Carboplatin in Adults With Advanced } \\
\text { Solid Tumors (MK-1775-001) }\end{array}$ & S & $\begin{array}{l}\text { AZD1775 + Gemcitabine } \\
\text { or Cisplatin or Carboplatin }\end{array}$ & C & 1 \\
\hline NCT02194829 & $\begin{array}{l}\text { Paclitaxel Albumin-Stabilized Nanoparticle Formulation and } \\
\text { Gemcitabine Hydrochloride With or Without WEE1 Inhibitor MK- } \\
1775 \text { in Treating Patients With Previously Untreated Pancreatic } \\
\text { Cancer That Is Metastatic or Cannot Be Removed by Surgery }\end{array}$ & S & $\begin{array}{l}\text { AZD-1775 + Gemcitabine } \\
+ \text { paclitaxel }\end{array}$ & ANR & 1,2 \\
\hline NCT02576444 & Olaparib Combinations & S & AZD1775 + olaparib & ANR & 2 \\
\hline NCT04197713 & $\begin{array}{l}\text { Testing the Sequential Combination of the Anti-cancer Drugs } \\
\text { Olaparib Followed by Adavosertib (AZD1775) in Patients With } \\
\text { Advanced Solid Tumors With Selected Mutations and PARP } \\
\text { Resistance, STAR Study }\end{array}$ & S & AZD1775 + olaparib & ANR & 1 \\
\hline NCT01922076 & $\begin{array}{l}\text { Adavosertib and Local Radiation Therapy in Treating Children } \\
\text { With Newly Diagnosed Diffuse Intrinsic Pontine Gliomas }\end{array}$ & S & $\begin{array}{l}\text { AZD1775 + Radiation } \\
\text { Therapy }\end{array}$ & ANR & 1 \\
\hline NCT03579316 & $\begin{array}{l}\text { Adavosertib With or Without Olaparib in Treating Patients With } \\
\text { Recurrent Ovarian, Primary Peritoneal, or Fallopian Tube Cancer }\end{array}$ & S & AZD1775 + olaparib & $\mathrm{R}$ & 2 \\
\hline NCT02095132 & $\begin{array}{l}\text { Adavosertib and Irinotecan Hydrochloride in Treating Younger } \\
\text { Patients With Relapsed or Refractory Solid Tumors }\end{array}$ & S & $\begin{array}{l}\text { AZD1775 + Irinotecan or } \\
\text { Irinotecan Hydrochloride }\end{array}$ & $\mathrm{R}$ & 1,2 \\
\hline NCT03345784 & $\begin{array}{l}\text { Adavosertib, External Beam Radiation Therapy, and Cisplatin in } \\
\text { Treating Patients With Cervical, Vaginal, or Uterine Cancer }\end{array}$ & S & $\begin{array}{l}\text { AZD1775 +Cisplatin + } \\
\text { Radiation (External Beam } \\
\text { Radiation Therapy) }\end{array}$ & R & 1 \\
\hline NCT01849146 & $\begin{array}{l}\text { Adavosertib, Radiation Therapy, and Temozolomide in Treating } \\
\text { Patients With Newly Diagnosed or Recurrent Glioblastoma }\end{array}$ & S & $\begin{array}{l}\text { AZD1775 + Radiation } \\
\text { Therapy + Temozolomide }\end{array}$ & R & 1 \\
\hline NCT02937818 & $\begin{array}{l}\text { A Phase II, Study to Determine the Preliminary Efficacy of Novel } \\
\text { Combinations of Treatment in Patients With Platinum Refractory } \\
\text { Extensive-Stage Small-Cell Lung Cancer }\end{array}$ & S & AZD1775 + carboplatin & ANR & 2 \\
\hline NCT02546661 & $\begin{array}{l}\text { Open-Label, Randomised, Multi-Drug, Biomarker-Directed, Phase } \\
\text { 1b Study in Pts w/ Muscle Invasive Bladder Cancer }\end{array}$ & S & AZD1775 + Durvalumab & ANR & 1 \\
\hline NCT02659241 & $\begin{array}{l}\text { Adavosertib Before Surgery in Treating Patients With Advanced } \\
\text { High Grade Ovarian, Fallopian Tube, or Primary Peritoneal Cancer }\end{array}$ & S & AZD1775 & $\mathrm{R}$ & 1 \\
\hline NCT02272790 & $\begin{array}{l}\text { Adavosertib Plus Chemotherapy in Platinum-Resistant Epithelial } \\
\text { Ovarian, Fallopian Tube, or Primary Peritoneal Cancer }\end{array}$ & S & $\begin{array}{l}\text { AZD1775 + Paclitaxel or } \\
\text { Carboplatin or }\end{array}$ & ANR & 2 \\
\hline
\end{tabular}


Table 4 Clinical trials evaluating WEE1/PKMYT1 inhibitor in monotherapy or in combination for cancer therapy (Continued)

\begin{tabular}{|c|c|c|c|c|c|}
\hline Study ID & Study title & Tumor & Interventions & Status & Phase \\
\hline & & & $\begin{array}{l}\text { Gemcitabine or pegylated } \\
\text { liposomal doxorubicin }\end{array}$ & & \\
\hline NCT02813135 & $\begin{array}{l}\text { European Proof-of-Concept Therapeutic Stratification Trial of } \\
\text { Molecular Anomalies in Relapsed or Refractory Tumors }\end{array}$ & $\mathrm{S} / \mathrm{H}$ & AZD1775 + carboplatin & $\mathrm{R}$ & 1,2 \\
\hline NCT03330847 & $\begin{array}{l}\text { To Assess Safety and Efficacy of Agents Targeting DNA Damage } \\
\text { Repair With Olaparib Versus Olaparib Monotherapy. }\end{array}$ & S & AZD1775 + olaparib & $\mathrm{R}$ & 2 \\
\hline NCT01827384 & $\begin{array}{l}\text { MPACT Study to Compare Effects of Targeted Drugs on Tumor } \\
\text { Gene Variations }\end{array}$ & $S$ & AZD1775 + carboplatin & R & 2 \\
\hline NCT02465060 & $\begin{array}{l}\text { Targeted Therapy Directed by Genetic Testing in Treating } \\
\text { Patients With Advanced Refractory Solid Tumors, Lymphomas, } \\
\text { or Multiple Myeloma (The MATCH Screening Trial) }\end{array}$ & $\mathrm{S} / \mathrm{H}$ & AZD1775 & $\mathrm{R}$ & 2 \\
\hline
\end{tabular}

$S$ solid tumor, $H$ hematological tumor, $C$ completed, $R$ recruiting, $W$ withdraw, ANR active not recruiting, $T$ terminated, NA status unknown (last update $04 / 22 / 2020)$

standard of care chemo/radiotherapy regimens depends on the generation of DNA damages in proliferating malignant cells. In this scenario, the overexpression or uncontrolled activation of DDR pathways has been showed to protect cancer cells from the therapeutic effect of DNA damaging agents. Moreover, a large number of preclinical studies highlighted that cancer cells depend on the functionality of DDR pathways in order to survive, to tolerate the replicative stress induced by the high proliferative rate and to sustain the intrinsic genetic instability. For these reasons, selective inhibitors have been developed in order to exploit cancer cells' dependency on DDR-gene functionality. Preclinical data has proven the efficacy of DDR inhibition in different kinds of hematological and solid tumors, both as monotherapy and in combination with a wide number of DNA damaging agents. Among DDR inhibitors, the most effective once are those targeting PARP1 and WEE1 family kinases. The effectiveness of PARP1 inhibitors is however dependent on homologous recombination (HR) repair deficiency while WEE1 family kinases inhibitors seems to have a widespread efficacy independently from a specific the genetic background. Indeed, cancer cells seem to be strictly dependent on the functionality of WEE1/PKMYT1 kinases to survive, especially those with alterations targeting the G1 checkpoint. WEE1/PKMYT1 kinases are involved in different biological processes and they seem to play diverse roles in nonmalignant and in cancer cells. Indeed, they control cell cycle regulation and genetic stability in nonmalignant cells and for these reasons act as tumor suppressor genes. Conversely, their ability of promote DNA damages repair and cell cycle control makes them act as pseudo-oncogenes in cancer cells. Several molecular studies showed that malignant cells have high expression level of WEE1 and PKMYT1, which has become a good prognostic biomarker for chemo/radiotherapy regimens. However, we currently lack information regarding predictive markers of response to WEE1/PKMYT1 inhibitors. Large preclinical and clinical studies should be conducted in order to identify specific molecular backgrounds in which the use of WEE1/
PKYMT1 inhibitors may be recommended. The identification of molecular vulnerabilities in cancer patients will be fundamental to design novel therapeutic regimens using WEE1/PKMYT1 inhibitors in a chemo/radiotherapy-free, synthetic lethality-based approach.

\section{Abbreviations \\ ALL: Acute lymphoblastic leukemia; AML: Acute myeloid leukemia; BC: Breast cancer; C: Chemotherapy; CC: Colorectal cancer; CN: Copy number; CNA: Copy number alteration; CLL: Chronic lymphocyte leukemia; \\ CML: Chronic myeloid leukemia; DDR: DNA damage response; DLBCL: Diffuse large B cell lymphoma; ES: Esophageal cancer; GC: Gastric cancer; \\ GL: Gliomas; GLB: Glioblastoma; HC: Hepatocellular carcinoma; \\ HR: Homologous recombination; HNSCC: Head and neck squamous cell carcinoma; LC: Lung cancer; M: Monotherapy; MaM: Malignant melanoma; MCL: Mantle cell lymphoma; MM: Multiple myeloma; MPF: Mitotic promoting factor; N: Neuroblastoma; NSCLC: Non-small-cell lung cancer; OC: Ovarian cancer; PC: Pancreatic cancer; R: Radiotherapy; S: Sarcomas; SAC: Spindle assembly checkpoint; TNBC: Triple-negative breast cancer}

\section{Acknowledgements}

Not applicable.

\section{Authors' contributions}

AGLDR, CC, and GS drafted the first version of the manuscript and created the figures. GM critically revised the manuscript for important intellectual content. All authors read and approved the final manuscript.

\section{Funding}

This work was supported by ERA-Per-Med (reference number: ERAPERME D2018-275).

\section{Availability of data and materials Not applicable.}

Ethics approval and consent to participate

Not applicable.

Consent for publication

All authors read and approved the final manuscript.

\section{Competing interests}

GM has competing interests with Novartis, BMS, Roche, Pfizer, ARIAD, and MSD. The other authors declare that they have no competing interests. 
Received: 18 June 2020 Accepted: 2 September 2020 Published online: 21 September 2020

\section{References}

1. Schmidt $M$, Rohe A, Platzer $C$, et al. Regulation of G2/M transition by inhibition of WEE1 and PKMYT1 Kinases. Molecules. 2017;22:2045.

2. Solc P, Schultz RM, Motlik J. Prophase I arrest and progression to metaphase I in mouse oocytes: Comparison of resumption of meiosis and recovery from G2-arrest in somatic cells. Mol Hum Reprod. 2010;16:654-64.

3. Nakanishi $M$, Ando $H$, Watanabe $N$, et al. Identification and characterization of human Wee1B, a new member of the Wee1 family of Cdk-inhibitory kinases. Genes Cells. 2000;5(10):839-47.

4. Mueller PR, Coleman TR, Kumagai A, Dunphy WG. Myt1: A membraneassociated inhibitory kinase that phosphorylates Cdc2 on both threonine-14 and tyrosine-15. Science. 1995;270(5233):86-90.

5. Booher RN, Holman PS, Fattaey A. Human Myt1 is a cell cycle-regulated kinase that inhibits Cdc2 but not Cdk2 activity. J Biol Chem. 1997;272(35): 22300-6.

6. Liu F, Stanton JJ, Wu Z, Piwnica-Worms H. The human Myt1 kinase preferentially phosphorylates Cdc2 on threonine 14 and localizes to the endoplasmic reticulum and Golgi complex. Mol Cell Biol. 1997;17(2):571-83.

7. Nakajima $H$, Yonemura S, Murata $M$, et al. Myt1 protein kinase is essential for Golgi and ER assembly during mitotic exit. J Cell Biol. 2008;181(1):89-103.

8. Chow JPH, Poon RYC, Ma HT. Inhibitory phosphorylation of cyclindependent kinase 1 as a compensatory mechanism for mitosis exit. Mol Cell Biol. 2011;31(7):1478-91.

9. Solomon MJ, Harper JW, Shuttleworth J. CAK, the p34cdc2 activating kinase contains a protein identical or closely related to p40MO15. EMBO J. 1993; 12(8):3133-42.

10. Lolli G, Johnson LN. CAK-Cyclin-dependent activating kinase: a key kinase in cell cycle control and a target for Drugs? Cell Cycle. 2005;4(4):572-7.

11. Walsh S, Margolis SS, Kornbluth S. Phosphorylation of the cyclin B1 cytoplasmic retention sequence by mitogen-activated protein kinase and Plx. Mol Cancer Res. 2003;1(4):280-9.

12. Szmyd R, Niska-Blakie J, Diril MK, et al. Premature activation of Cdk1 leads to mitotic events in S phase and embryonic lethality. Oncogene. 2019;38(7): 998-1018.

13. Watanabe $N$, Arai H, Nishihara $Y$, et al. M-phase kinases induce phosphodependent ubiquitination of somatic Wee1 by SCFbeta-TrCP. Proc Natl Acad Sci U S A. 2004;101(13):4419-24.

14. Toyoshima-Morimoto F, Taniguchi E, Shinya N, et al. Polo-like kinase 1 phosphorylates cyclin B1 and targets it to the nucleus during prophase. Nature. 2001;410(6825):215-20.

15. Van Vugt MATM, Brás A, Medema RH. Polo-like kinase-1 controls recovery from a G2 DNA damage-induced arrest in mammalian cells. Mol Cell. 2004; 15(5):799-811.

16. Nakojima H, Toyoshima-Morimoto F, Taniguchi E, Nishida E. Identification of a consensus motif for PIK (Polo-like kinase) phosphorylation reveals Myt1 as a Plk1 substrate. J Biol Chem. 2003;278(28):25277-80.

17. Takisawa H, Mimura S, Kubota Y. Eukaryotic DNA replication: from prereplication complex to initiation complex. Curr Opin Cell Biol. 2000;12(6): 690-6.

18. Heller RC, Kang S, Lam WM, et al. Eukaryotic origin-dependent DNA replication in vitro reveals sequential action of DDK and S-CDK kinases. Cell. 2011;146(1):80-91.

19. Labib K. How do Cdc7 and cyclin-dependent kinases trigger the initiation of chromosome replication in eukaryotic cells? Genes Dev. 2010;24(12):1208-19.

20. Gu Y, Rosenblatt J, Morgan DO. Cell cycle regulation of CDK2 activity by phosphorylation of Thr160 and Tyr15. EMBO J. 1992;11(11):3995-4005.

21. Vassilopoulos A, Tominaga $Y$, Kim HS, et al. WEE1 murine deficiency induces hyper-activation of APC/C and results in genomic instability and carcinogenesis. Oncogene. 2015;34(23):3023-35.

22. Ghelli Luserna Di Rorà A, Martinelli G, Simonetti G. The balance between mitotic death and mitotic slippage in acute leukemia: a new therapeutic window? J Hematol Oncol. 2019;12(1):123.

23. Visconti R, Grieco D. Fighting tubulin-targeting anticancer drug toxicity and resistance. Endocr Relat Cancer. 2017;24(9):T107-17.

24. Visconti R, Palazzo L, Della Monica R, Grieco D. Fcp1-dependent dephosphorylation is required for M-phase-promoting factor inactivation at mitosis exit. Nat Commun. 2012;3:894.
25. Musacchio A, Salmon ED. The spindle-assembly checkpoint in space and time. Nat Rev Mol Cell Biol. 2007;8(5):379-93.

26. Visconti R, Palazzo L, Pepe A, et al. The end of mitosis from a phosphatase perspective. Cell Cycle. 2013;12(1):17-9.

27. Martín Y, Domínguez-Kelly R, Freire R. Novel insights into maintaining genomic integrity: Wee1 regulating Mus81/Eme1. Cell Div. 2011;6:21.

28. Domínguez-Kelly R, Martín Y, Koundrioukoff $S$, et al. Wee1 controls genomic stability during replication by regulating the Mus81-Eme1 endonuclease. J Cell Biol. 2011;194(4):567-79.

29. Duda H, Arter M, Gloggnitzer J, et al. A mechanism for controlled breakage of under-replicated chromosomes during mitosis. Dev Cell. 2016;39(6):740-55.

30. Asquith CRM, Laitinen T, East MP. PKMYT1: a forgotten member of the WEE1 family. Nat Rev Drug Discov. 2020;19(3):157.

31. Liu Y, Qi J, Dou Z, et al. Systematic expression analysis of WEE family kinases reveals the importance of PKMYT1 in breast carcinogenesis. Cell Prolif. 2020; 53(2):e12741.

32. Jeong D, Kim H, Kim D, et al. Protein kinase, membrane-associated tyrosine/ threonine 1 is associated with the progression of colorectal cancer. Oncol Rep. 2018;39(6):2829-36.

33. Lal S, Cozzitorto JA, Blanco F, et al. 988 Sequence alterations in the WEE1 non-coding region is a facilitator and marker for pancreatic tumorigenesis. Gastroenterology. 2014;S-1034.

34. Ciriello G, Miller ML, Aksoy BA, et al. Emerging landscape of oncogenic signatures across human cancers. Nat Genet. 2013;45(10):1127-33.

35. Ghelli Luserna Di Rorà A, Beeharry N, Imbrogno E, et al. Targeting WEE1 to enhance conventional therapies for acute lymphoblastic leukemia. J Hematol Oncol. 2018;11(1):99.

36. Barbosa RSS, Dantonio PM, Guimarães T, et al. Sequential combination of bortezomib and WEE1 inhibitor, MK-1775, induced apoptosis in multiple myeloma cell lines. Biochem Biophys Res Commun. 2019;519(3):597-604.

37. Van Linden AA, Baturin D, Ford JB, et al. Inhibition of Wee1 sensitizes cancer cells to antimetabolite chemotherapeutics in vitro and in vivo, independent of p53 functionality. Mol Cancer Ther. 2013;12(12):2675-84.

38. Porter CC, Kim J, Fosmire S, et al. Integrated genomic analyses identify WEE1 as a critical mediator of cell fate and a novel therapeutic target in acute myeloid leukemia. Leukemia. 2012;26(6):1266-76.

39. Johnston HE, Carter MJ, Larrayoz M, et al. Proteomics profiling of CLL versus healthy B-cells identifies putative therapeutic targets and a subtypeindependent signature of spliceosome dysregulation. Mol Cell Proteomics. 2018;17(4):776-91.

40. Neben K, Schnittger S, Brors B, et al. Distinct gene expression patterns associated with FLT3- and NRAS-activating mutations in acute myeloid leukemia with normal karyotype. Oncogene. 2005;24(9):1580-8.

41. Zhou $L$, Zhang $Y$, Chen S, et al. A regimen combining the Wee1 inhibitor AZD1775 with HDAC inhibitors targets human acute myeloid leukemia cells harboring various genetic mutations. Leukemia. 2015;29(4):807-18.

42. Fan J, Li L, Small D, Rassool F. Cells expressing FLT3/ITD mutations exhibit elevated repair errors generated through alternative NHEJ pathways: implications for genomic instability and therapy. Blood. 2010;116(24):5298-305.

43. De Jong MRW, Visser $L$, Huls $G$, et al. Identification of relevant drugable targets in diffuse large B-cell lymphoma using a genome-wide unbiased CD20 guilt-by association approach. PLoS One. 2018;13(2):e0193098.

44. Bolomsky A, Gruber F, Stangelberger K, et al. Preclinical validation studies support causal machine learning based identification of novel drug targets for high-risk multiple myeloma. Blood. 2018;132(Supplement 1):3210.

45. Sun QS, Luo M, Zhao HM, Sun H. Overexpression of PKMYT1 indicates the poor prognosis and enhances proliferation and tumorigenesis in non-small cell lung cancer via activation of Notch signal pathway. Eur Rev Med Pharmacol Sci. 2019:23(10):4210-9.

46. Liu L, Wu J, Wang S, et al. PKMYT1 promoted the growth and motility of hepatocellular carcinoma cells by activating beta-catenin/TCF signaling. Exp Cell Res. 2017;358(2):209-16.

47. Wang XM, Li QY, Ren LL, et al. Effects of MCRS1 on proliferation, migration, invasion, and epithelial mesenchymal transition of gastric cancer cells by interacting with Pkmyt1 protein kinase. Cell Signal. 2019:59:171-81.

48. Kim HY, Cho Y, Kang HG, et al. Targeting the WEE1 kinase as a molecular targeted therapy for gastric cancer. Oncotarget. 2016;7(31):49902-16.

49. Magnussen Gl, Holm R, Emilsen E, et al. High expression of Wee1 is associated with poor disease-free survival in Malignant Melanoma: Potential for targeted therapy. PLoS One. 2012;7(6):e38254. 
50. Mueller S, Hashizume R, Yang X, et al. Targeting wee1 for the treatment of pediatric high-grade gliomas. Neuro Oncol. 2014;16(3):352-60.

51. Mir SE, De Witt Hamer PC, Krawczyk PM, et al. In silico analysis of kinase expression identifies WEE1 as a gatekeeper against mitotic catastrophe in glioblastoma. Cancer Cell. 2010;18(3):244-57.

52. Chayka O, D'Acunto CW, Middleton O, et al. Identification and pharmacological inactivation of the MYCN gene network as a therapeutic strategy for neuroblastic tumor cells. J Biol Chem. 2015;290(4):2198-212.

53. Zhang Q, Zhao X, Zhang C, et al. Overexpressed PKMYT1 promotes tumor progression and associates with poor survival in esophageal squamous cell carcinoma. Cancer Manag Res. 2019;11:7813-24.

54. Tibes R, Bogenberger JM, Chaudhuri L, et al. RNAi screening of the kinome with cytarabine in leukemias. Blood. 2012;119(12):2863-72.

55. Simonetti G, Padella A, do Valle IF, et al. Aneuploid acute myeloid leukemia exhibits a signature of genomic alterations in the cell cycle and protein degradation machinery. Cancer. 2018;125:1-14.

56. Caretti $V$, Hiddingh $L$, Lagerweij $T$, et al. WEE1 kinase inhibition enhances the radiation response of diffuse intrinsic pontine gliomas. Mol Cancer Ther. 2013;12(2):141-50

57. Music D, Dahlrot RH, Hermansen SK, et al. Expression and prognostic value of the WEE1 kinase in gliomas. J Neurooncol. 2016;127(2):381-9.

58. Egeland EV, Flatmark K, Nesland JM, et al. Expression and clinical significance of Wee1 in colorectal cancer. Tumor Biol. 2016;37(9):12133-40.

59. Slipicevic A, Holth A, Hellesylt E, et al. Wee1 is a novel independent prognostic marker of poor survival in post-chemotherapy ovarian carcinoma effusions. Gynecol Oncol. 2014;135(1):118-24.

60. Shu C, Wang Q, Yan X, Wang J. Whole-genome expression microarray combined with machine learning to identify prognostic biomarkers for high-grade glioma. J Mol Neurosci. 2018;64(4):491-500.

61. Novak EM, Halley NS, Gimenez TM, et al. BLM germline and somatic PKMY $\mathrm{T} 1$ and AHCY mutations: genetic variations beyond MYCN and prognosis in neuroblastoma. Med Hypotheses. 2016;97:22-5.

62. Ku BM, Bae Y-H, Koh J, et al. Mutational status of TP53 defines the efficacy of Wee1 inhibitor AZD1775 in KRAS -mutant non-small cell lung cancer. Oncotarget. 2017:8(40):67526-37.

63. Bauman JE, Chung $\mathrm{CH}$. CHK it out! Blocking WEE kinase routs TP53 mutant cancer. Clin Cancer Res. 2014;20(16):4173-5.

64. Kreahling JM, Foroutan P, Reed D, et al. Wee1 inhibition by MK-1775 leads to tumor inhibition and enhances efficacy of gemcitabine in human sarcomas. PLoS One. 2013;8(3):e57523.

65. Ford JB, Baturin D, Burleson TM, et al. AZD1775 sensitizes T cell acute lymphoblastic leukemia cells to cytarabine by promoting apoptosis over DNA repair. Oncotarget. 2015;6(29):28001-10.

66. Webster PJ, Littlejohns AT, Gaunt HJ, et al. AZD1775 induces toxicity through double-stranded DNA breaks independently of chemotherapeutic agents in p53-mutated colorectal cancer cells. Cell Cycle. 2017;16(22):2176-82.

67. Kahen E, Yu D, Harrison DJ, et al. Identification of clinically achievable combination therapies in childhood rhabdomyosarcoma. Cancer Chemother Pharmacol. 2016:78(2):313-23.

68. Lee YY, Cho YJ, Shin SW, et al. Anti-tumor effects of Wee1 kinase inhibitor with radiotherapy in human cervical cancer. Sci Rep. 2019;9(1):15394.

69. PosthumaDeBoer J, Würdinger T, Graat HCA, et al. WEE1 inhibition sensitizes osteosarcoma to radiotherapy. BMC Cancer. 2011;11(1):156

70. Xu H, Krystal GW. Actinomycin D decreases Mcl-1 expression and acts synergistically with ABT-737 against small cell lung cancer cell lines. Clin Cancer Res. 2010;16(17):4392-400.

71. Hayashi Y, Fujimura A, Kato K, et al. Nucleolar integrity during interphase supports faithful Cdk1 activation and mitotic entry. Sci Adv. 2018:4(6): eaap7777.

72. Alexander VM, Roy M, Steffens KA, et al. Azacytidine induces cell cycle arrest and suppression of neuroendocrine markers in carcinoids. Int J Clin Exp Med. 2010;3(2):95-102.

73. Uchida R, Yokota S, Matsuda D, et al. Habiterpenol, a novel abrogator of bleomycin-induced G2 arrest in Jurkat cells, produced by Phytohabitans suffuscus 3787-5. J Antibiot (Tokyo). 2014;67(11):777-81.

74. Zhang Z, Zhang $\mathrm{H}, \mathrm{Hu}$ Z, et al. Synergy of 1,25-dihydroxyvitamin D3 and carboplatin in growth suppression of SKOV-3 cells. Oncol Lett. 2014;8(3): 1348-54.

75. Sarin N, Engel F, Kalayda GV, et al. Cisplatin resistance in non-small cell lung cancer cells is associated with an abrogation of cisplatin-induced G2/M cell cycle arrest. PLoS One. 2017;12(7):e0181081.
76. Chen D, Lin X, Gao J, et al. Wee1 Inhibitor AZD1775 Combined with cisplatin potentiates anticancer activity against gastric cancer by increasing DNA damage and cell apoptosis. Biomed Res Int. 2018;2018:5813292.

77. Zheng H, Shao F, Martin S, et al. WEE1 inhibition targets cell cycle checkpoints for triple negative breast cancers to overcome cisplatin resistance. Sci Rep. 2017:7:43517.

78. de Jong MRW, Langendonk M, Reitsma B, et al. WEE1 inhibition synergizes with CHOP chemotherapy and radiation therapy through induction of premature mitotic entry and DNA damage in diffuse large B-cell lymphoma. Ther Adv Hematol. 2020;11:2040620719898373.

79. Ma J, Li X, Su Y, et al. Mechanisms responsible for the synergistic antileukemic interactions between ATR inhibition and cytarabine in acute myeloid leukemia cells. Sci Rep. 2017;7:41950.

80. Shi Z, Azuma A, Sampath D, et al. S-phase arrest by nucleoside analogues and abrogation of survival without cell cycle progression by 7 hydroxystaurosporine. Cancer Res. 2001;61(3):1065-72.

81. Garcia TB, Fosmire SP, Porter CC. Increased activity of both CDK1 and CDK2 is necessary for the combinatorial activity of WEE1 inhibition and cytarabine. Leuk Res. 2018;64:30-3.

82. Al-Aamri HM, Ku H, Irving HR, et al. Time dependent response of daunorubicin on cytotoxicity, cell cycle and DNA repair in acute lymphoblastic leukaemia. BMC Cancer. 2019;19(1):179.

83. Shang $D, \operatorname{Han} T, X u X$, Liu Y. Decitabine induces $G 2 / M$ cell cycle arrest by suppressing p38/NF-kB signaling in human renal clear cell carcinoma. Int J Clin Exp Pathol. 2015;8(9):11140-8.

84. Singh SK, Banerjee $S, A c o s t a ~ E P$, et al. Resveratrol induces cell cycle arrest and apoptosis with docetaxel in prostate cancer cells via a p53/p21WAF1/ CIP1 and p27KIP1 pathway. Oncotarget. 2017;8(10):17216-28.

85. Morse DL, Gray H, Payne CM, Gillies RJ. Docetaxel induces cell death through mitotic catastrophe in human breast cancer cells. Mol Cancer Ther 2005;4(10):1495-504

86. Vera J, Raatz Y, Wolkenhauer $\mathrm{O}$, et al. Chk1 and Wee1 control genotoxicstress induced G2-M arrest in melanoma cells. Cell Signal. 2015;27(5):951-60.

87. $W u ~ C L$, Ping SY, Yu CP, Yu DS. Tyrosine kinase receptor inhibitor-targeted combined chemotherapy for metastatic bladder cancer. Kaohsiung J Med Sci. 2012;28(4):194-203.

88. Senthebane DA, Jonker T, Rowe A, et al. The role of tumor microenvironment in chemoresistance: 3D extracellular matrices as accomplices. Int J Mol Sci. 2018;19(10):2861.

89. Chen $\mathrm{X}$, Low KH, Alexander $\mathrm{A}$, et al. Cyclin E overexpression sensitizes triplenegative breast cancer to Wee1 kinase inhibition. Clin Cancer Res. 2018; 24(24):6594-610.

90. Seung HL, Seung MS, Dong JS, et al. Epothilones induce human colon cancer SW620 cell apoptosis via the tubulin polymerization-independent activation of the nuclear factor-kB/lkB kinase signal pathway. Mol Cancer Ther. 2007;6(10):2786-97.

91. Zhang $R$, Zhu L, Zhang $L$, et al. PTEN enhances $G 2 / M$ arrest in etoposidetreated MCF-7 cells through activation of the ATM pathway. Oncol Rep. 2016:35(5):2707-14

92. Pitts TM, Simmons DM, Bagby SM, et al. Wee1 inhibition enhances the antitumor effects of capecitabine in preclinical models of triple-negative breast cancer. Cancers. 2020;12(3):719.

93. Rajeshkumar NV, De Oliveira E, Ottenhof N, et al. MK-1775, a potent Wee1 inhibitor, synergizes with gemcitabine to achieve tumor regressions, selectively in p53-deficient pancreatic cancer xenografts. Clin Cancer Res. 2011;17(9):2799-806

94. Koh SB, Wallez Y, Dunlop CR, et al. Mechanistic distinctions between CHK1 and WEE1 inhibition guide the scheduling of triple therapy with gemcitabine. Cancer Res. 2018;78(11):3054-66.

95. Xu B, Sun Z, Liu Z, et al. Replication stress induces micronuclei comprising of aggregated DNA double-strand breaks. PLoS One. 2011;6(4):e18618.

96. Aarts M, Sharpe R, Garcia-Murillas I, et al. Forced mitotic entry of S-phase cells as a therapeutic strategy induced by inhibition of WEE1. Cancer Discov. 2012;2(6):524-39.

97. Morgan MA, Onono FO, Spielmann HP, et al. Modulation of anthracyclineinduced cytotoxicity by targeting the prenylated proteome in myeloid leukemia cells. J Mol Med. 2012;90(2):149-61.

98. Subhash W, Tan SH, Yeo MS, et al. ATM expression predicts veliparib and irinotecan sensitivity in gastric cancer by mediating p53independent regulation of cell cycle and apoptosis. Mol Cancer Ther. 2016;15(12):3087-96. 
99. Yin $Y$, Shen $Q$, Tao R, et al. Wee1 inhibition can suppress tumor proliferation and sensitize p53 mutant colonic cancer cells to the anticancer effect of irinotecan. Mol Med Rep. 2018;17(2):3344-9.

100. Jan YH, Heck DE, Laskin DL, Laskin JD. Sulfur mustard analog mechlorethamine (Bis(2-chloroethyl)methylamine) modulates cell cycle progression via the DNA damage response in human lung epithelial A549 cells. Chem Res Toxicol. 2019;32(6):1123-33.

101. Mahbub A, Le Maitre C, Haywood-Small S, et al. Dietary polyphenols influence antimetabolite agents: Methotrexate, 6-mercaptopurine and 5fluorouracil in leukemia cell lines. Oncotarget. 2017;8(62):104877-93.

102. Costantini DL, Villani DF, Vallis KA, Reilly RM. Methotrexate, paclitaxel, and doxorubicin radiosensitize HER2-amplified human breast cancer cells to the auger electron-emitting radiotherapeutic agent 111 In-NLS-trastuzumab. J Nucl Med. 2010;51(3):477-83.

103. Di Rorà AGL, Bocconcelli M, Ferrari $A$, et al. Synergism through WEE1 and CHK1 inhibition in acute lymphoblastic leukemia. Cancers (Basel). 2019; 11(11):1654.

104. Guerriero E, Sorice A, Capone F, et al. Vitamin C effect on mitoxantroneinduced cytotoxicity in human breast cancer cell lines. PLoS One. 2014; 9(12):e115287.

105. Voland C, Bord A, Péleraux A, et al. Repression of cell cycle-related proteins by oxaliplatin but not cisplatin in human colon cancer cells. Mol Cancer Ther. 2006:5(9):2149-57.

106. Lal S, Zarei M, Chand SN, et al. WEE1 inhibition in pancreatic cancer cells is dependent on DNA repair status in a context dependent manner. Sci Rep. 2016;6:33323.

107. George J, Banik NL, Ray SK. Molecular mechanisms of taxol for induction of cell death in glioblastomas. In: Ray S, editor. Glioblastoma. New York: Springer; 2010. https://doi.org/10.1007/978-1-4419-0410-2_14.

108. Lewis CW, Jin Z, Macdonald D, et al. Prolonged mitotic arrest induced by Wee1 inhibition sensitizes breast cancer cells to paclitaxel. Oncotarget. 2017; 8(43):73705-22.

109. Chen KC, Yang TY, Wu CC, et al. Pemetrexed induces S-phase arrest and apoptosis via a deregulated activation of Akt signaling pathway. PLoS One. 2014;9(5):e97888.

110. Hirai H, Arai T, Okada M, et al. MK-1775, a small molecule Wee1 inhibitor, enhances antitumor efficacy of various DNA-damaging agents, including 5fluorouracil. Cancer Biol Ther. 2010;9(7):514-22.

111. Maier P, Hartmann L, Wenz F, Herskind C. Cellular pathways in response to ionizing radiation and their targetability for tumor radiosensitization. Int J Mol Sci. 2016;17(1):102

112. Li J, Chen W, Zhang P, Li N. Topoisomerase II trapping agent teniposide induces apoptosis and G2/M or $\mathrm{S}$ phase arrest of oral squamous cell carcinoma. World J Surg Oncol. 2006;4:41

113. Wotring LL, Roti Roti JL. Thioguanine-induced $\mathrm{S}$ and $\mathrm{G} 2$ blocks and their significance to the mechanism of cytotoxicity. Cancer Res. 1980; 40(5):1458-62.

114. Nguyen D, Zajac-Kaye M, Rubinstein $L$, et al. Poly(ADP-ribose) polymerase inhibition enhances p53-dependent and -independent DNA damage responses induced by DNA damaging agent. Cell Cycle. 2011;10(23):4074-82

115. Shumway SD, Kubica JL, Guertin AD, et al. Abstract 2969: a Wee1 kinase inhibitor, MK-1775, sensitizes cervical carcinoma cell lines to cisplatin and topotecan. Cancer Res. 2011;71(8 Supplement):2969.

116. Brandl MB, Pasquier E, Li F, et al. Computational analysis of image-based drug profiling predicts synergistic drug combinations: applications in triplenegative breast cancer. Mol Oncol. 2014;8(8):1548-60.

117. Tu Y, Cheng S, Zhang S, et al. Vincristine induces cell cycle arrest and apoptosis in SH-SY5Y human neuroblastoma cells. Int J Mol Med. 2013; 31(1):113-9

118. Visconti R, Della Monica R, Palazzo L, et al. The Fcp1-Wee1-Cdk1 axis affects spindle assembly checkpoint robustness and sensitivity to antimicrotubule cancer drugs. Cell Death Differ. 2015;22(9):1551-60.

119. Zhu JY, Cuellar RA, Berndt N, et al. Structural basis of Wee kinases functionality and inactivation by diverse small molecule inhibitors. J Med Chem. 2017;60(18):7863-75.

120. Restelli V, Chilà R, Lupi M, et al. Characterization of a mantle cell lymphoma cell line resistant to the Chk1 inhibitor PF-00477736. Oncotarget. 2015;6(35): 37229-40.

121. Qi W, Xie C, Li C, et al. CHK1 plays a critical role in the anti-leukemic activity of the wee1 inhibitor MK-1775 in acute myeloid leukemia cells. J Hematol Oncol. 2014;7(1):53.
122. Young LA, O'Connor LO, de Renty C, et al. Differential activity of ATR and Wee1 inhibitors in a highly sensitive subpopulation of DLBCL linked to replication stress. Cancer Res. 2019;79(14):3762-75.

123. Bridges KA, Hirai $H$, Buser CA, et al. MK-1775, a novel wee1 kinase inhibitor, radiosensitizes p53-defective human tumor cells. Clin Cancer Res. 2011; 17(17):5638-48.

124. Ma H, Takahashi A, Sejimo Y, et al. Targeting of carbon ion-induced G2 checkpoint activation in lung cancer cells using Wee-1 inhibitor MK-1775. Radiat Res. 2016:185(2):e52.

125. Lindenblatt D, Terraneo N, Pellegrini G, et al. Combination of lutetium-177 labelled anti-L1CAM antibody ChCE7 with the clinically relevant protein kinase inhibitor MK1775: a novel combination against human ovarian carcinoma. BMC Cancer. 2018;18(1):922.

126. Parsels LA, Karnak D, Parsels JD, et al. PARP1 Trapping and DNA replication stress enhance radiosensitization with combined WEE1 and PARP inhibitors. Mol Cancer Res. 2018;16(2):222-32.

127. Caldwell JT, Edwards H, Buck SA, et al. Targeting the wee1 kinase for treatment of pediatric Down syndrome acute myeloid leukemia. Pediatr Blood Cancer. 2014;61(10):1767-73.

128. Xing $L$, Lin $L$, $Y u T$, et al. A novel BCMA PBD-ADC with ATM/ATR/WEE1 inhibitors or bortezomib induce synergistic lethality in multiple myeloma. Leukemia. 2020. https://doi.org/10.1038/s41375-020-0745-9.

129. Tibes $R$, Ferreira Coutinho D, Tuen MT, et al. DNA damage repair interference By WEE1 inhibition with AZD1775 overcomes combined azacitidine and Venetoclax resistance in acute myeloid leukmeia (AML). Blood. 2019;134(Supplement_1):2559.

130. Qi W, Zhang W, Edwards H, et al. Synergistic anti-leukemic interactions between panobinostat and MK-1775 in acute myeloid leukemia ex vivo. Cancer Biol Ther. 2015;16(12):1784-93.

131. Tanaka N, Patel AA, Tang $L$, et al. Replication stress leading to apoptosis within the S-phase contributes to synergism between vorinostat and AZD1775 in HNSCC harboring high-risk TP53 mutation. Clin Cancer Res. 2017;23(21):6541-54

132. Qi W, Xu X, Wang M, et al. Inhibition of Wee1 sensitizes AML cells to ATR inhibitor VE-822-induced DNA damage and apoptosis. Biochem Pharmacol. 2019:164:273-82.

133. Restelli V, Lupi M, Chila R, et al. DNA damage response inhibitor combinations exert synergistic antitumor activity in aggressive B-cell lymphomas. Mol Cancer Ther. 2019;18(7):1255-64.

134. Bukhari AB, Lewis CW, Pearce JJ, et al. Inhibiting Wee1 and ATR kinases produces tumor-selective synthetic lethality and suppresses metastasis. Clin Invest. 2019;129(3):1329-44.

135. Jin J, Fang $H$, Yang F, et al. Combined inhibition of ATR and WEE1 as a novel therapeutic strategy in triple-negative breast cancer. Neoplasia (United States). 2018:20(5):478-88.

136. Weisberg E, Nonami A, Chen Z, et al. Identification of Wee1 as a novel therapeutic target for mutant RAS-driven acute leukemia and other malignancies. Leukemia. 2014;29(1):27-37.

137. Li F, Guo E, Huang J, et al. mTOR inhibition overcomes primary and acquired resistance to Wee1 inhibition by augmenting replication stress in epithelial ovarian cancers. Am J Cancer Res. 2020;10(3):908-24.

138. Sen $T$, Tong $P$, Diao $L$, et al. Targeting AXL and mTOR pathway overcomes primary and acquired resistance to WEE1 inhibition in small-cell lung cancer. Clin Cancer Res. 2017;23(20):6239-54.

139. Hai J, Liu S, Bufe L, et al. Synergy of WEE1 and mTOR inhibition in mutant KRAS-driven lung cancers. Clin Cancer Res. 2017;23(22):6993-7005.

140. Chila R, Basana A, Lupi M, et al. Combined inhibition of Chk1 and Wee1 as a new therapeutic strategy for mantle cell lymphoma. Oncotarget. 2015;6(5): 3394-408.

141. Restelli V, Vagni M, Arribas AJ, et al. Inhibition of CHK1 and WEE1 as a new therapeutic approach in diffuse large B cell lymphomas with MYC deregulation. Br J Haematol. 2018;181(1):129-33.

142. Chaudhuri L, Vincelette ND, Koh BD, et al. CHK1 and WEE1 inhibition combine synergistically to enhance therapeutic efficacy in acute myeloid leukemia ex vivo. Haematologica. 2014;99(4):688-96.

143. De Jong MRW, Langendonk M, Reitsma B, et al. WEE1 inhibition enhances anti-apoptotic dependency as a result of premature mitotic entry and DNA damage. Cancers (Basel). 2019;11(11):1743.

144. Fang Y, McGrail DJ, Sun C, et al. Sequential therapy with PARP and WEE1 inhibitors minimizes toxicity while maintaining efficacy. Cancer Cell. 2019; 35(6):851-867.e7. 
145. Lallo A, Frese KK, Morrow CJ, et al. The combination of the PARP inhibitor olaparib and the WEE1 Inhibitor AZD1775 as a new therapeutic option for small cell lung cancer. Clin Cancer Res. 2018;24(20):5153-64.

146. Garcia TB, Snedeker JC, Baturin D, et al. A small-molecule inhibitor of WEE1, AZD1775, synergizes with olaparib by impairing homologous recombination and enhancing DNA damage and apoptosis in acute leukemia. Mol Cancer Ther. 2017;16(10):2058-68.

147. Lee JW, Parameswaran J, Sandoval-Schaefer T, et al. Combined aurora kinase A (AURKA) and WEE1 inhibition demonstrates synergistic antitumor effect in squamous cell carcinoma of the head and neck. Clin Cancer Res. 2019;25(11):3430-42.

148. Chen $G$, Zhang $B, X u H$, et al. Suppression of Sirt1 sensitizes lung cancer cells to WEE1 inhibitor MK-1775-induced DNA damage and apoptosis. Oncogene. 2017;36(50):6863-72.

149. Francis AM, Alexander A, Liu Y, et al. CDK4/6 inhibitors sensitize Rb-positive sarcoma cells to Wee1 kinase inhibition through reversible cell-cycle arrest. Mol Cancer Ther. 2017;16(9):1751-64.

150. Takashima Y, Kikuchi E, Kikuchi J, et al. Bromodomain and extraterminal domain inhibition synergizes with WEE1-inhibitor AZD1775 effect by impairing nonhomologous end joining and enhancing DNA damage in nonsmall cell lung cancer. Int J Cancer. 2020;146(4):1114-24.

151. Panek RL, Lu GH, Klutchko SR, et al. In vitro pharmacological characterization of PD 166285, a new nanomolar potent and broadly active protein tyrosine kinase inhibitor. J Pharmacol Exp Ther. 1997; 283(3):1433-44.

152. Duan L, Perez RE, Hansen M, et al. Increasing cisplatin sensitivity by scheduledependent inhibition of AKT and Chk1. Cancer Biol Ther. 2014; 15(12):1600-12.

153. Blackwood E, Epler J, Yen I, et al. Combination drug scheduling defines a "window of opportunity" for chemopotentiation of gemcitabine by an orally bioavailable, selective ChK1 inhibitor, GNE-900. Mol Cancer Ther. 2013; 12(10):1968-80.

154. Levinson NM, Boxer SG. Structural and spectroscopic analysis of the kinase inhibitor bosutinib and an isomer of bosutinib binding to the Abl tyrosine kinase domain. PLoS One. 2012;7(4):e29828.

155. Beeharry N, Banina E, Hittle J, et al. Re-purposing clinical kinase inhibitors to enhance chemosensitivity by overriding checkpoints. Cell Cycle. 2014;13(14): 2172-91.

156. Mendez E, Rodriguez CP, Kao MC, et al. A phase I clinical trial of AZD1775 in combination with neoadjuvant weekly docetaxel and cisplatin before definitive therapy in head and neck squamous cell carcinoma. Clin Cancer Res. 2018;24(12):2740-8.

157. Do K, Wilsker D, Ji J, et al. Phase I study of single-agent AZD1775 (MK-1775), a wee1 kinase inhibitor, in patients with refractory solid tumors. J Clin Oncol. 2015:33(30):3409-15.

158. Leijen S, Van Geel RMJM, Pavlick AC, et al. Phase I study evaluating WEE1 inhibitor AZD1775 as monotherapy and in combination with gemcitabine cisplatin, or carboplatin in patients with advanced solid tumors. J Clin Oncol. 2016;34(36):4371-80.

159. Leijen S, Van Geel RMJM, Sonke GS, et al. Phase II study of WEE1 inhibitor AZD1775 plus carboplatin in patientswith tp53-mutated ovarian cancer refractory or resistant to first-line therapy within 3 months. J Clin Oncol. 2016;34(36):4354-61.

160. Moore KN, Chambers SK, Hamilton EP, et al. Adavosertib with chemotherapy $(\mathrm{CT})$ in patients (pts) with platinum-resistant ovarian cancer (PPROC): an open label, four-arm, phase II study. J Clin Oncol. 2019;5( suppl):5513.

161. Yap TA, Plummer R, Azad NS, Helleday T. The DNA damaging revolution: PARP inhibitors and beyond. Am Soc Clin Oncol Educ B. 2019;39:185-95.

162. Forment JV, O'Connor MJ. Targeting the replication stress response in cancer. Pharmacol Ther. 2018;188:155-67.

163. Fu S, Wang Y, Keyomarsi K, Meric-Bernstein F. Strategic development of AZD1775, a Wee1 kinase inhibitor, for cancer therapy. Expert Opin Investig Drugs. 2018;27(9):741-51.

164. Qiu Z, Oleinick NL, Zhang J. ATR/CHK1 inhibitors and cancer therapy. Radiother Oncol. 2018;126(3):450-64.

165. Ghelli Luserna Di Rora A, lacobucci I, Martinelli G. The cell cycle checkpoint inhibitors in the treatment of leukemias. J Hematol Oncol. 2017;10(1):77.

166. Lewis CW, Bukhari AB, Xiao EJ, et al. Upregulation of MyT1 promotes acquired resistance of cancer cells to WEE1 inhibition. Cancer Res. 2019; 79(23):5971-85.
167. Garcia TB, Uluisik RC, van Linden AA, et al. Increased HDAC activity and cMYC expression mediate acquired resistance to WEE1 inhibition in acute leukemia. Front Oncol. 2020;10:296.

\section{Publisher's Note}

Springer Nature remains neutral with regard to jurisdictional claims in published maps and institutional affiliations.
Ready to submit your research? Choose BMC and benefit from:

- fast, convenient online submission

- thorough peer review by experienced researchers in your field

- rapid publication on acceptance

- support for research data, including large and complex data types

- gold Open Access which fosters wider collaboration and increased citations

- maximum visibility for your research: over $100 \mathrm{M}$ website views per year

At BMC, research is always in progress.

Learn more biomedcentral.com/submissions 